\title{
TREMATODE PARASITE CERCARIAE AS FOOD IN MODEL FRESHWATER TROPHIC INTERACTIONS.
}

By

\author{
Ben Schultz
}

Bachelor of Science, 2016, Laurentian University

\author{
A thesis \\ presented to Ryerson University \\ in partial fulfillment of the \\ requirements for the degree of \\ Master of Applied Science \\ in the Program of
}

Environmental Applied Science and Management

Toronto, Ontario, Canada, 2018

(C) Ben Schultz 2018 


\begin{abstract}
Author's Declaration
I hereby declare that I am the sole author of this thesis. This is a true copy of the thesis, including any required final revisions, as accepted by my examiners.

I authorize Ryerson University to lend this thesis to other institutions or individuals for the purpose of scholarly research

I further authorize Ryerson University to reproduce this thesis by photocopying or by other means, in total or in part, at the request of other institutions or individuals for the purpose of scholarly research.
\end{abstract}

I understand that my thesis may be made electronically available to the public. 


\begin{abstract}
Trematode parasite cercariae as food in model freshwater trophic interactions. Master of Applied Science
\end{abstract}

2018

Ben Schultz

Environmental Applied Science and Management

Ryerson University

Free-living parasite stages are important but often overlooked components of ecosystems, especially their role(s) in food webs. Trematode parasites have complex life cycles that include a motile transmission phase, cercariae, that are produced in great quantities within aquatic snail hosts and join the zooplankton community after emerging. Here I examined how cercariae presence affected the population abundance of a common freshwater zooplanktonic animal (Daphnia) when predators were present. I also sought to determine the pathways taken by cercariae-derived carbon within a model freshwater food web by using the stable isotope ${ }^{13} \mathrm{C}$ as a tracer. I found that Daphnia population abundance positively benefitted from cercariae presence when larval dragonfly predators were present, serving as alternate prey. I also found that ${ }^{13} \mathrm{C}$ was an effective tool to track the flow of cercarial carbon, demonstrating high consumption by benthic consumers, as well as the utility of this method for use in future studies. 


\section{Acknowledgments}

I first owe a huge debt of gratitude to my supervisor, Dr. Janet Koprivnikar, for her continued effort and support in getting me through these past two years. To say I could not have done it without her would be an understatement, and if it were not for her aid and mentoring, this paper would not have been possible. I have yet to see her lose her temper (though at times it may have been warranted), and that patience and positivity definitely played an integral role throughout this writing process.

To my committee members, Dr. Michael Arts and Dr. Stephanie Melles, I would like to extend my thanks for the advice and excellent committee meetings; and a big thanks to Michael for allowing me to use his lab space at the MaRS Discovery District.

I send my thanks to my undergraduate help, Lucy and Jamie, who provided enjoyable conversations and invaluable aid in the field. As well, thanks to my lab mates, Keira, who shared in many field sampling trips and discussions, and Mary, who sat through many graduate classes beside me.

Finally, I thank my parents, siblings and fiancé, for the much-needed financial support, encouragement and love they provided. 


\section{Table of Contents}

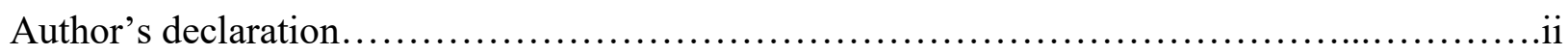

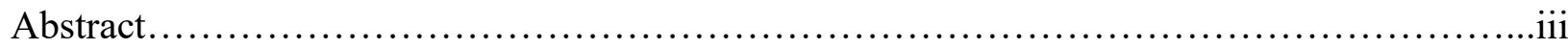

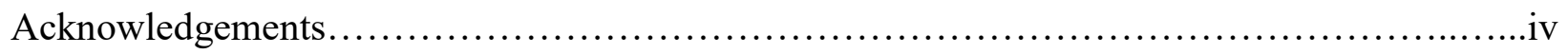

List of figures.............................................................

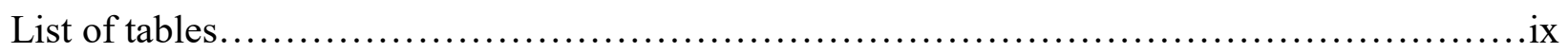

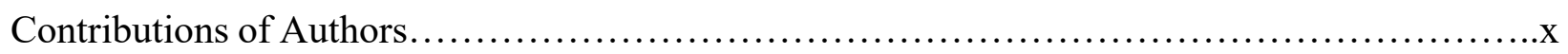

Chapter 1: An introduction to macroparasites and their ecology $\ldots \ldots \ldots \ldots \ldots \ldots \ldots \ldots \ldots \ldots \ldots . \ldots \ldots$

Parasites and predator-prey dynamics.........................................

Parasites with complex life cycles.............................................

Parasites and food webs ......................................................

Characteristics of trematode cercariae .........................................

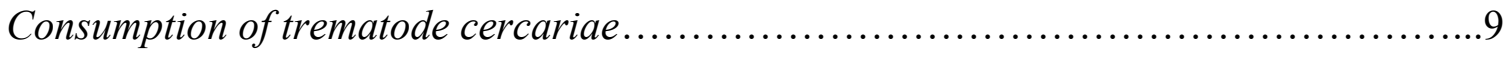

Interactions among trematodes, larval odonates, and zooplankton .....................13

Approaches to studying aquatic trophic interactions ............................... 14

Thesis aims..........................................................16

Chapter 2: The beneficial impact of trematode infectious stages on zooplankton populations in the

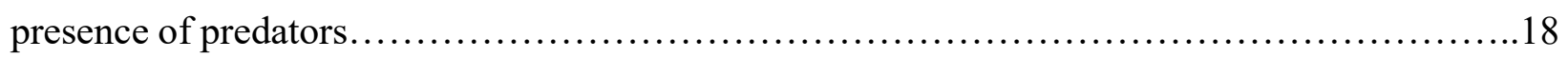

Abstract.................................................................... 18 
Introduction.

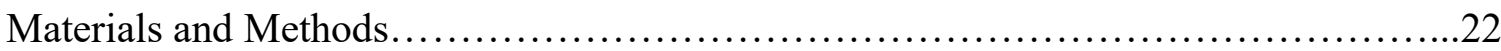

Experimental Design and Procedure........................................22

Data Collection........................................................27

Statistical Analysis.................................................27

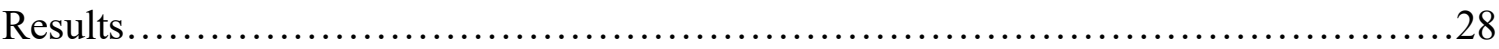

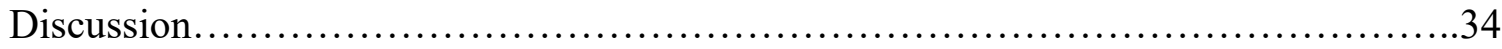

Chapter 3: The contribution of trematode cercariae to carbon cycling in freshwater habitats.......37

Abstract.................................................................. 37

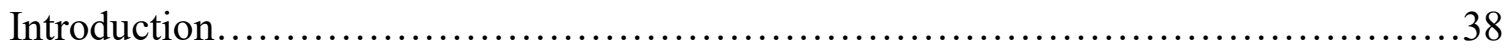

Materials and Methods....................................................42

Experimental Design .............................................42

Animal Collection.....................................................43

Cercariae ${ }^{13}$ C labeling................................................44

Sample Collection and Analysis .........................................46

Statistical Analysis.................................................48

Results.................................................................. 50

Discussion.............................................................. 52 
Chapter 4: General Discussion...

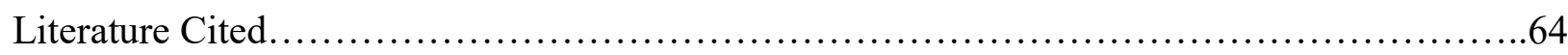




\section{List of Figures}

\section{Chapter 1}

Figure 1-1: Life cycle of two digenetic trematodes....................................4

Figure 1-2: Cercariae from various trematode species................................ 8

\section{Chapter 2}

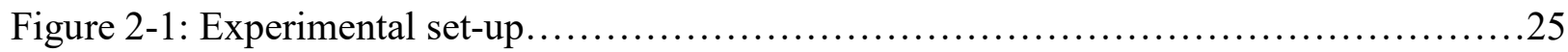

Figure 2-2: Mean number of Daphnia over all treatments.............................. 30

Figure 2-3: Mean number of Daphnia with predators.................................. 31

Figure 2-4: Mean number of Daphnia with parasites....................................32

Figure 2-5: Mean number of Daphnia with all taxa......................................

\section{Chapter 3}

Figure 3-1: Mean (+ S.E.) value of $\delta 13 \mathrm{C}$ resulting from stable isotope analysis...............51 


\section{List of Tables}

\section{Chapter 1}

Table 1-1: List of potential or confirmed predators of cercariae.....................10,11,12

\section{Chapter 3}

Table 3-1: Mean values of $\delta 13 \mathrm{C}$ resulting from stable isotope analysis......................49 


\section{Contributions of Authors}

This thesis is presented in manuscript format: chapters 2 and 3 are in preparation to be submitted to peer-reviewed journals as stand-alone papers. The following people were contributors to the formation of the manuscripts included within this thesis:

Ben Schultz (Candidate): primary author, performed experimental set-up, data collection, and analysis.

Dr. Janet Koprivnikar (Supervisor): conceptual design of experiments, advised on methods of statistical analyses, editor and reviewer of manuscripts. 


\section{Chapter 1: An Introduction to Macroparasites and their Ecology}

Parasites are a ubiquitous component of most ecosystems (Dobson et al., 2008), infecting invertebrates and vertebrates alike, and are important owing to their effects at multiple biological levels. At the individual level, they can have major detrimental impacts on their hosts, such as reducing their fitness (Sorci and Clobert, 1995) and causing stress that affects the host's immune system (Møller, 1998). These can have far-reaching effects beyond that of an individual host, including influences on host population dynamics (McCallum and Dobson, 1995). For instance, parasites can increase the juvenile mortality rate of their host species, and this can create intense selection pressure (Møller, 1998). Parasites are thus an important consideration for host evolution owing to the constant arms-race between hosts and parasites, with natural selection driving each side to gain a competitive edge against the other (Ebert, 1994).

The competition between host and parasite has implications on a greater scale when considering the communities and ecosystems in which these interactions occur. Infected hosts may have altered interactions with their surrounding community through changes in their behaviours or other traits, which can greatly impact dynamics like predator-prey relationships (Mouritsen and Poulin, 2002). Behavioural changes in parasitized hosts that affect their survival can also create empty ecological niches in the habitat, whereby the absence of a once-common but afflicted species allows competing species to settle in and take over (Mouritsen and Poulin, 2002). Parasites have consequently been suggested to play important roles in the maintenance of

free-living biodiversity by influencing key forces such as interspecific competition and predation (Combes, 1996; Hatcher et al., 2006), the latter of which will be further explored below.

At the ecosystem level, food webs are intricate constructs that help to explain fundamental ecological processes such as energy flow, biodiversity, and trophic interactions 
(Pascual and Dunne, 2006). Energy flow can be described as the transfer of matter and energy from one trophic level to another, and the interactions among them (Rigler, 1975). Because parasites are so common, with some estimates suggesting that they comprise as much as $40 \%$ of total biodiversity (Rohde, 1982), they should be included as integral members of food webs. Given the incredible number of possible trophic interactions in which a given parasitic species could be involved, especially for those with complex multi-host life cycles that involve freeliving stages, they could serve both as a source of food and a detriment to species at several trophic levels (Marcogliese and Cone, 1997). Given that host diversity typically begets parasite diversity (Hetchinger and Lafferty, 2005; Johnson et al., 2016), the presence of key parasites within a community may even be an indicator of the health of the ecosystem by virtue of its ability to support high host biodiversity (Marcogliese, 2005; Hudson et al., 2006).

\section{Parasites and predator-prey dynamics}

As will be detailed for trematode parasites (flatworm helminths below), many parasites have complex life cycles that require more than one host for their completion, and often involve trophic transmission (i.e. consumption of an infected host). The life cycles of such parasites may include one or more free-living infectious stages, and asexual and sexual reproduction in intermediate and definitive hosts, respectively (Thomas et al., 1997). Through infection, parasites can both help and hinder predation. For instance, by decreasing the size of a host population, parasites may reduce the number of prey below a threshold capable of sustaining a predator (Hatcher et al., 2006). At the same time, a parasite with multiple hosts may shift predation from one host species in favor of another (Hatcher et al., 2006). Behavioural changes in a host species due to infection may increase their susceptibility to consumption by a predator, in some cases to allow the parasite to progress into its definitive host (Lafferty and Morris, 1996; Seppälä et al., 
2004). It is important to note that these predator-prey cases all deal with the consequences of consuming an infected host, rather than in the context of a parasite as prey itself. Parasites with complex life cycles

Trematodes are flatworms (Phylum Platyhelminthes) that form a highly diverse and abundant group of parasites in many aquatic ecosystems, particularly those in the subclass Digenea (Esch et al., 2002). Trematodes typically have complex life cycles that include several hosts and two different free-living phases (Esch et al., 2002; Cribb et al., 2003)(Figure 1-1). 


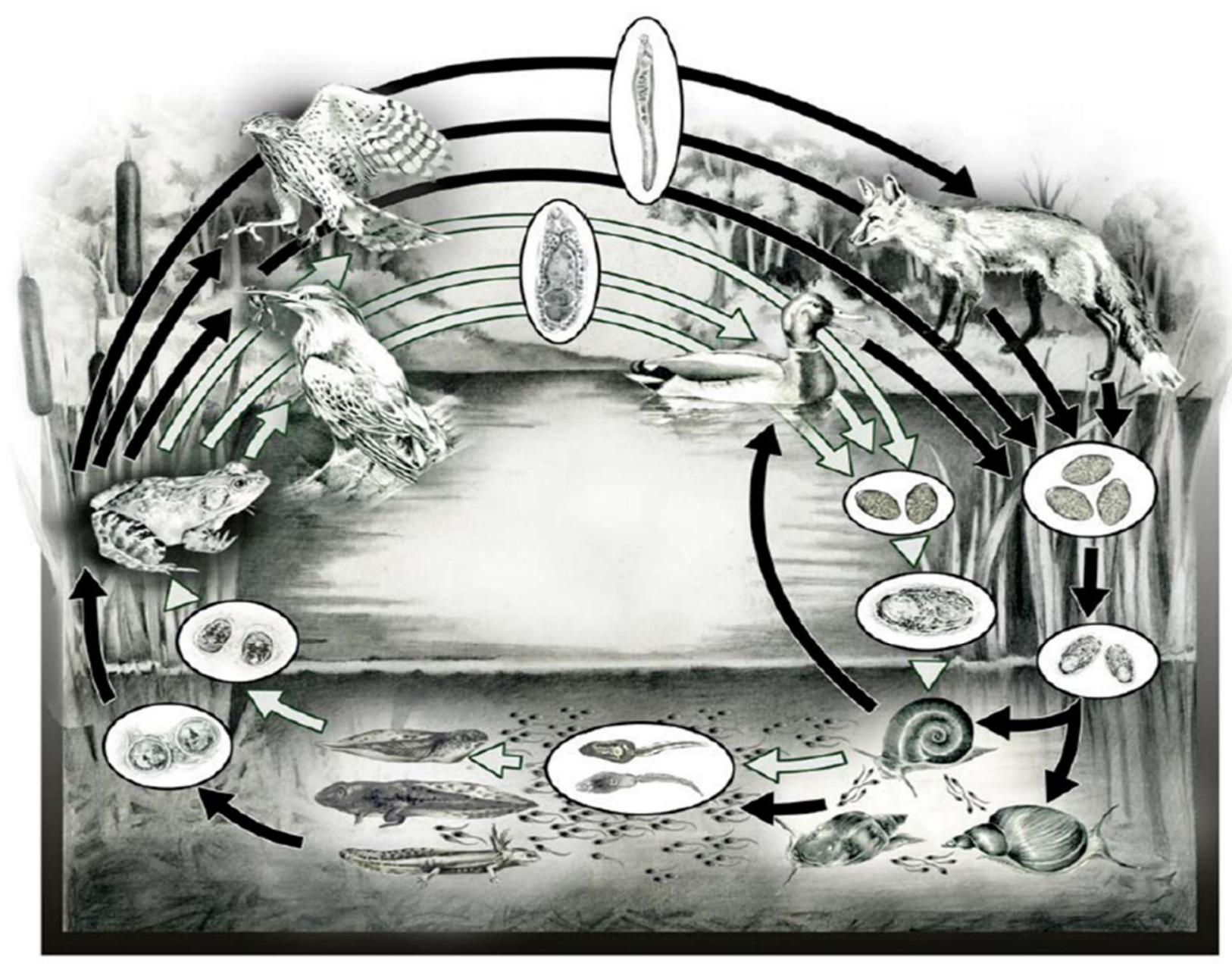

Figure 1-1: Life cycle of two digenetic trematodes (Ribeiroia ondatrae and Echinostoma trivolvis, grey and black arrows, respectively) illustrating the use of multiple hosts in freshwater habitats. 
Vertebrates such as birds and mammals typically serve as the definitive/final host of these flatworms. Sexual reproduction takes place within these hosts, producing eggs that hatch into miracidia. When infected fecal matter is deposited into aquatic habitats, the motile miracidia seek out their first intermediate host (almost always a mollusc). Aquatic snails are a common first intermediate host, and it is during this portion of the life cycle that a second motile infectious stage (a cercaria) is produced en masse by sporocysts or rediae through asexual reproduction within the snail (Morley, 2012). When the cercariae emerge from their host snail, they seek out a second intermediate host in which to encyst, often a larval amphibian or a fish, or an invertebrate such as an aquatic arthropod (Esch et al., 2002). The cercariae do not feed, instead living from their glycogen reserves, thus most have a short lifespan $(<24 \mathrm{~h})$ (Morley, 2012). Like the miracidia, the free-living cercaria phase is directly vulnerable to environmental stressors such as temperature, water quality, and predation (Pietrock and Marcogliese, 2003). If successful, an encysted cercaria (a metacercaria) will complete the life cycle when a suitable final host predates upon an infected second intermediate host; however, the odds of doing so are extremely low (Wojdak et al., 2014). This means that the majority of trematode cercariae ultimately have another fate, including being predated upon or dying. Because of this complex life cycle with both free-living and within-host stages, the importance of such parasites can extend far beyond that of infection itself, especially when one considers the large biomass represented by larval trematode stages.

\section{Parasites and food webs}

The inclusion of trematodes into aquatic food webs is particularly important because of their sheer biomass. The biomass of larval stages represented by the within-snail reproductive phases (rediae and sporocysts) and cercariae is especially significant and can account for almost 
$90 \%$ of total trematode biomass in a freshwater system considering that as much as one third of the snail population may be infected (Preston et al., 2013). Compared to common aquatic freshwater insects like beetles (Coleoptera), dragonflies (Odonata), and giant water bugs (Hemiptera), trematode cercariae are equal or greater in aggregate biomass (Preston et al., 2013). Within eutrophic ponds, the biomass of all produced cercariae in a year can be as great as 4.65 tonnes, likened to the mass of an adult Asian elephant (Soldánová et al., 2016). Freshwater systems are not the only habitats containing vast amounts of cercarial biomass; marine ecosystems like estuaries may contain large quantities of cercariae equivalent to the mass of local fish and bird populations (Kuris et al., 2008).

However, the cryptic and complex nature of many parasite life cycles presents a challenge when attempting to assess their role(s) in food webs and may be why few food webs to date have included parasites in any form despite the estimation that they are involved in $75 \%$ of the trophic links in some ecosystems (Dobson et al., 2008; Lafferty et al., 2008). As detailed above, parasites should be included in food webs because they are known to directly or indirectly affect trophic interactions via the death or reduced competitiveness of infected hosts, particularly altering predator-prey relationships (Mouritsen and Poulin, 2002). However, free-living infectious stages, such as those represented by trematode cercariae, could also have a major impact as part of the zooplankton community in the water column (Morley, 2012) because they are also subject to predation or death from starvation to become detritus. As trematode cercariae can differ greatly in their morphological characteristics (See figure 1-2), there may be considerable variation in their likelihood of predation. 


\section{Characteristics of trematode cercariae}

The size range of cercariae differs over the vast number of trematode species described to date, but generally they can be as small as $0.2 \mathrm{~mm}$ and as large as $2 \mathrm{~mm}$ (Cort, 1914; Morley, 2012) (Figure 1-2). In single pond, cercariae from as many as 18 different species of trematode have been reported as present at any one time, resulting in huge variation in their availability as prey (Loy and Haas, 2001). Considering the large biomass of freshwater trematodes, the potential for energy transfer is quite large if cercariae are consumed by predators or detrivores (Johnson et al., 2010). Most cercariae do not successfully infect hosts, and if not consumed by predators, they will die after expending their energy stores (Preston et al., 2013). Given their estimated biomass, cercariae may thus represent a substantial contribution to energy flow and nutrient cycling in aquatic ecosystems such that their population dynamics could impact a far greater number of species in this manner than currently accounted for in food webs (Soldánová et al., 2016). It is therefore important to consider the various implications of predation upon cercariae. 

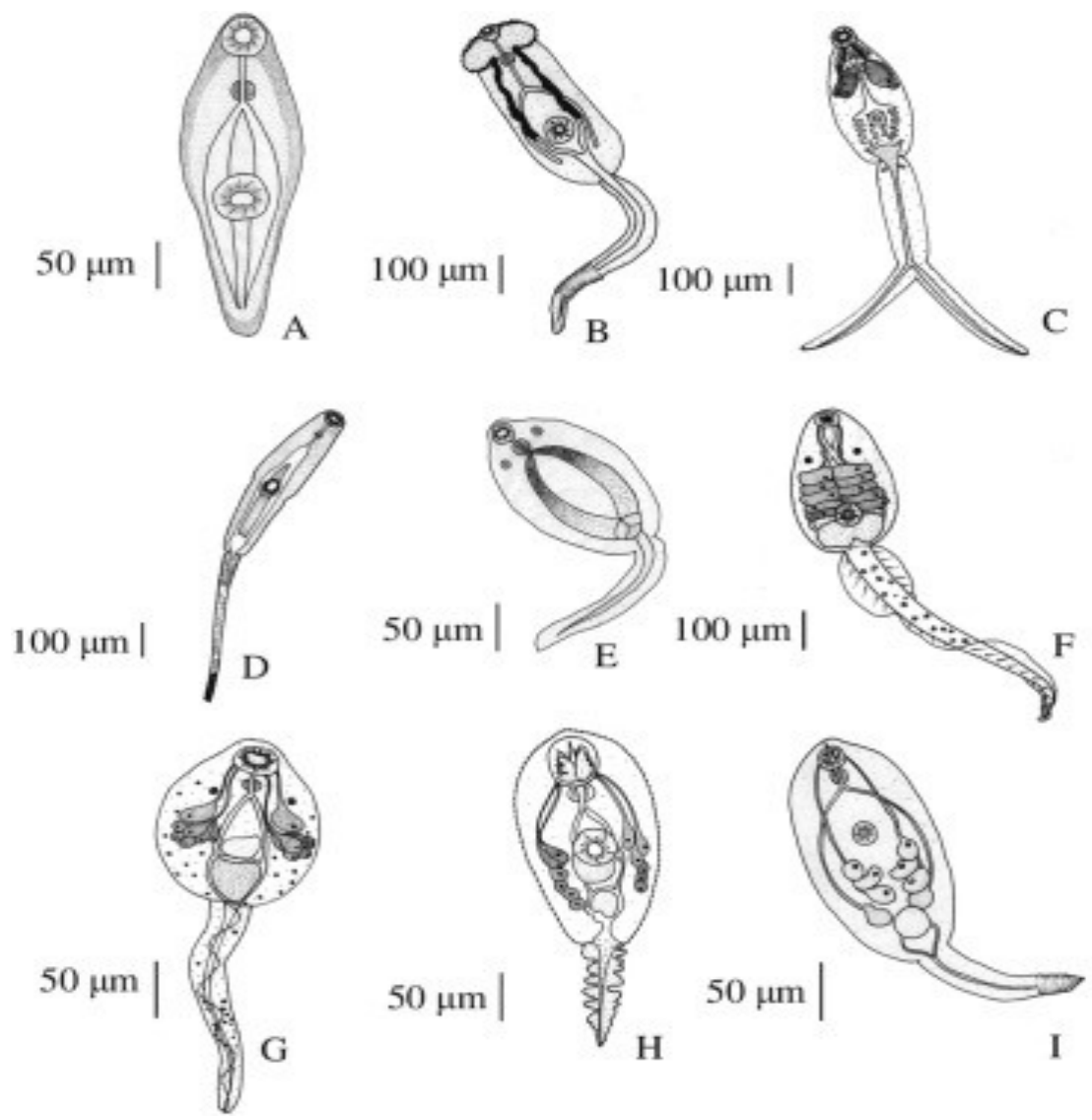

Figure 1-2: Cercariae from various trematode species showing a diversity of morphologies and sizes. (from Anucherngchai et al., 2016). 


\section{Consumption of trematode cercariae}

While some free-living parasite stages seek out ingestion by appropriate hosts as part of their transmission, other non-host predators will actively consume and digest them (Johnson et al., 2010). Cercariae are likely sought after by predators because they are natural sources of energy-rich glycogen (Morley, 2012), and also contain stores of sterols and lipids that may make them worthwhile prey (Marsit et al., 2000). The cercariae of many trematode species also fall within the size range of other zooplankton that serve as prey (Morley, 2012).

To date, many aquatic invertebrates (e.g., larval insects, oligochaetes, and copepods), as well as vertebrates like fish, have been demonstrated to predate upon cercariae (Morley, 2012; Orlofske et al., 2012; Orlofske et al., 2015; Thieltges et al., 2013)(Table 1-1). However, many of these species are assumed, but not confirmed, to predate upon cercariae owing to their similarity in size with other common zooplanktonic prey (Rohr et al., 2015). These studies have also generally only focused on a few species of trematodes (Orlofske et al., 2015; Rohr et al., 2015), while there many be as many as 18 different species of trematode present in a pond (Loy and Haas, 2001). 
Table 1-1: List of potential or confirmed freshwater predators and which species of trematode they were tested with.

\begin{tabular}{|c|c|c|}
\hline $\begin{array}{c}\text { Tested \& possible } \\
\text { predators of cercariae (or } \\
\text { snails) } \\
\end{array}$ & cercariae species & citation \\
\hline $\begin{array}{l}\text { Guppy (Lebistes } \\
\text { reticulatus) }\end{array}$ & Schistosoma mansoni & $\begin{array}{l}\text { Rowan, } 1958 \text { and } \\
\text { Knight et al., } 1970\end{array}$ \\
\hline Daphnia pulex & S. mansoni & Christensen, 2009 \\
\hline Daphnia longispina & S. mansoni & Christensen, 2009 \\
\hline $\begin{array}{l}\text { Notodromas monacha } \\
\text { (ostracod) }\end{array}$ & S. mansoni & Christensen, 2009 \\
\hline $\begin{array}{l}\text { Cypria ophthalmica } \\
\text { (ostracod) }\end{array}$ & S. mansoni & Christensen, 2009 \\
\hline Hydra spp. & Ribeiroia ondatrae & $\begin{array}{l}\text { Schotthoefer et al., } \\
2007\end{array}$ \\
\hline $\begin{array}{l}\text { damselfly (Odonata, } \\
\text { Coenagrionidae) larvae }\end{array}$ & R. ondatrae & $\begin{array}{l}\text { Schotthoefer et al., } \\
2007\end{array}$ \\
\hline $\begin{array}{l}\text { dragonfly (Odonata, } \\
\text { Libellulidae) larvae }\end{array}$ & R. ondatrae & $\begin{array}{l}\text { Schotthoefer et al., } \\
2007\end{array}$ \\
\hline Copepods (Cyclopoida) & $R$. ondatrae & $\begin{array}{l}\text { Schotthoefer et al., } \\
2007\end{array}$ \\
\hline $\begin{array}{l}\text { California newt larvae } \\
\text { (Taricha torosa) }\end{array}$ & $R$. ondatrae & Orlofske et al., 2012 \\
\hline $\begin{array}{l}\text { Western mosquitofish } \\
\text { (Gambusia affinis) }\end{array}$ & R. ondatrae & Orlofske et al., 2012 \\
\hline $\begin{array}{l}\text { Damselfly larvae } \\
\text { (Enallagma spp. or Lestes } \\
\text { spp.) }\end{array}$ & R. ondatrae & Orlofske et al., 2012 \\
\hline $\begin{array}{l}\text { Dragonfly nymphs (Anax } \\
\text { sp.) }\end{array}$ & $R$. ondatrae & Orlofske et al., 2012 \\
\hline $\begin{array}{l}\text { California clam shrimp } \\
\text { (Cyzicus californicus) }\end{array}$ & R. ondatrae & Orlofske et al., 2012 \\
\hline $\begin{array}{l}\text { Backswimmers (Notonecta } \\
\text { sp.) }\end{array}$ & $R$. ondatrae & Orlofske et al., 2012 \\
\hline Clams (Sphaerium sp.) & R. ondatrae & Orlofske et al., 2012 \\
\hline $\begin{array}{l}\text { Dytiscidae (diving water } \\
\text { beetle) }\end{array}$ & assumed & Rohr et al., 2015 \\
\hline $\begin{array}{l}\text { Hydrophilidae (water } \\
\text { scavenger beetle) }\end{array}$ & assumed & Rohr et al., 2015 \\
\hline
\end{tabular}




\begin{tabular}{|l|l|l|}
\hline $\begin{array}{l}\text { Chaoboridae (phantom } \\
\text { midges/glass worms as } \\
\text { larvae) }\end{array}$ & assumed & Rohr et al., 2015 \\
\hline $\begin{array}{l}\text { Belostomatidae (giant } \\
\text { water bugs) }\end{array}$ & assumed & Rohr et al., 2015 \\
\hline Corixidae (water boatmen) & assumed & Rohr et al., 2015 \\
\hline Nepidae (water scorpion) & assumed & Rohr et al., 2015 \\
\hline $\begin{array}{l}\text { Notonectidae } \\
\text { (backswimmers) }\end{array}$ & assumed & Rohr et al., 2015 \\
\hline $\begin{array}{l}\text { Pleidae (pygmy } \\
\text { backswimmers) }\end{array}$ & assumed & Rohr et al., 2015 \\
\hline $\begin{array}{l}\text { Coenagrionidae (narrow- } \\
\text { winged damselflies) }\end{array}$ & assumed & Rohr et al., 2015 \\
\hline Amphipods (Amphipoda) & assumed & Rohr et al., 2015 \\
\hline Crayfish (Astacidea) & assumed & Rohr et al., 2015 \\
\hline $\begin{array}{l}\text { Anax junius } \text { larva (family } \\
\text { Aeshnidae, dragonfly) }\end{array}$ & Echinostoma trivolvis & Rohr et al., 2015 \\
\hline $\begin{array}{l}\text { Erythemus simplicicolis } \\
\text { larva (dragonfly) }\end{array}$ & E. trivolvis & Rohr et al., 2015 \\
\hline $\begin{array}{l}\text { Sympetrum semicinctum } \\
\text { larva (family Libellulidae, } \\
\text { dragonfly) }\end{array}$ & E. trivolvis & Rohr et al., 2015 \\
\hline $\begin{array}{l}\text { Western mosquitofish } \\
\text { (Gambusia affinis) }\end{array}$ & Magnacauda sp. & Orlofske et al., 2015 \\
\hline $\begin{array}{l}\text { Western mosquitofish } \\
\text { (Gambusia affinis) }\end{array}$ & R. ondatrae & Orlofske et al., 2015 \\
\hline $\begin{array}{l}\text { Western mosquitofish } \\
\text { (Gambusia affinis) }\end{array}$ & E. trivolvis & Orlofske et al., 2015 al., 2015 \\
\hline $\begin{array}{l}\text { Western mosquitofish } \\
\text { (Gambusia affinis) }\end{array}$ & $\begin{array}{l}\text { Cephalogonimus } \\
\text { americanus }\end{array}$ \\
\hline $\begin{array}{l}\text { Damselfly nymphs } \\
\text { (Enallagma } \text { spp.) }\end{array}$ & Magnacauda sp. \\
\hline $\begin{array}{l}\text { Damselfly nymphs } \\
\text { (Enallagma } \text { spp.) }\end{array}$ & R. ondatrae \\
\hline $\begin{array}{l}\text { Damselfly nymphs } \\
\text { (Enallagma spp.) } \\
\text { (Enallagma } \text { spp.) }\end{array}$ & E. trivolvis \\
\hline
\end{tabular}




\begin{tabular}{|l|l|l|}
\hline $\begin{array}{l}\text { Chaetogaster limnaei } \\
\text { (oligochaete worm) }\end{array}$ & Fasciola hepatica & Rajasekariah 1978 \\
\hline $\begin{array}{l}\text { Chaetogaster limnaei } \\
\text { (oligochaete worm) }\end{array}$ & S. mansoni & Michelson 1964 \\
\hline $\begin{array}{l}\text { Chaetogaster limnaei } \\
\text { (oligochaete worm) }\end{array}$ & E. trivolvis & Hopkins et al., 2013 \\
\hline $\begin{array}{l}\text { Candonocypris } \\
\text { novaezelandiae (ostracod) }\end{array}$ & S. mansoni & Yousif et al., 2013 \\
\hline
\end{tabular}


While cercariae may not make up the primary prey for many of these freshwater predators listed in Table 1-1, several factors can affect their consumption. For instance, optimal foraging results in size-mediated predation that causes relatively smaller dragonfly larvae to consume cercariae more often than large larvae who instead prefer bigger prey such as Daphnia (Catania et al., 2016). Cercariae also vary considerably in size among trematode species, and some are more readily consumed than others (Orlofske et al., 2012; Orlofske et al., 2015). Below I summarize the current state of knowledge regarding trophic interactions of trematode cercariae with two key groups in many small freshwater ecosystems such as ponds, larval odonates and zooplankton.

Interactions among trematodes, larval odonates, and zooplankton

Dragonflies and damselflies (Odonata) are insects that spend their immature lives as fully aquatic larvae, metamorphosing into aerial predators as adults. These larval stages are found in great abundance in littoral habitats, acting as important predators of other freshwater organisms owing to their high population densities (Wissinger, 1988a). Due to the non-synchronous timing of adult dragonfly reproduction, larvae can be represented by several different sizes during any given season; this allows the larvae to consume a large variety of prey, including other odonate larvae (Wissinger, 1988b). Dragonfly larvae are predators of various planktonic animals. They voraciously consume Daphnia, a genus of planktonic crustaceans found in freshwater ecosystems (Burks et al., 2001). Dragonfly larvae will also readily consume trematode cercariae: in laboratory feeding experiments, they have been shown to consume $50-90 \%$ of the cercariae given to them within 10 minutes of exposure (Schotthoeffer et al., 2007). This is important in the context of parasite transmission because the consumption of cercariae by predators such as 
dragonfly larvae may effectively reduce the odds of second intermediate hosts (e.g., fish and larval amphibians) becoming infected (Orlofske et al., 2012).

Cercariae could both negatively and positively impact zooplankton communities. For instance, common freshwater zooplankton such as Daphnia, copepods, and amphipods have been shown to consume cercariae in the water column (Christensen, 2009). However, some trematodes can infect larger individuals of some Daphnia species, reducing their reproductive success (Schwartz and Cameron, 1993). This in turn has repercussions if trematodes negatively affect zooplankton populations because the latter are good sources of carbon, nitrogen and phosphorous, serving as critical food sources for many aquatic animals such as fish, arthropods, and amphibians (Anderson and Hessen, 1991). Conversely, trematode cercariae may augment zooplankton populations if they serve as alternative prey for larval odonates and reduce predation pressure on zooplankton. In natural settings, predation pressures are so strong on Daphnia populations that they undergo diel vertical migration to avoid pelagic predators (Burks et al., 2001). This movement toward the benthic zone overlaps with odonate larva populations, and a marked drop in the abundance of Daphnia occurs as a result of their predation (Burks et al., 2001). In lab settings, four dragonfly larvae can effectively consume at least 50 individual Daphnia in 24 hours (Burks et al., 2001). However, it is not known how predation by large macroinvertebrates such as larval odonates will affect zooplankton populations such as Daphnia when cercariae are also present.

\section{Approaches to studying aquatic trophic interactions}

Although there are many ways in which trophic interactions, energy flow, and nutrient cycling may be examined in aquatic ecosystems, here I outline the general use of stable isotope analysis (SIA) for such purposes. Naturally occurring stable isotopes like $\delta^{15} \mathrm{~N}$ and $\delta^{13} \mathrm{C}$ can be 
used as an aid in determining both trophic position and dynamics within a given ecosystem when a general baseline is established (Vander Zanden and Rasmussen, 1999; Post, 2002). Of the two stable isotopes of carbon $\left({ }^{12} \mathrm{C}\right.$ and $\left.{ }^{13} \mathrm{C}\right),{ }^{12} \mathrm{C}$ is far more common, with a ratio of $98.9: 1.1$ (Rounick and Winterbourn, 1986). The common ${ }^{12} \mathrm{C}$ standard used in stable isotope analysis was historically Pee Dee Belemnite (PDB), and is now commonly the synthetic Vienna PDB (VPDB, with the notation delta ' $\delta$ ' standing for the parts per thousand deviation of ${ }^{13} \mathrm{C}$ within a sample from such a standard (Kendall and Caldwell, 1998)

A ratio of stable isotopes within an ecosystem can therefore act as a baseline from which an observer can measure a spike that takes the ratio $\delta$ outside its normal threshold (Rounick and Winterbourn, 1986). For instance, phytoplankton and algae in aquatic systems tend to have distinct ${ }^{13} \mathrm{C} /{ }^{12} \mathrm{C}$ ratios (i.e. $\delta^{13} \mathrm{C}$ ) that can be used to investigate the local food web (Vander Zanden and Rasmussen, 1999). Because benthic algae generally contain a lower ratio of ${ }^{13} \mathrm{C} /{ }^{12} \mathrm{C}$ relative to phytoplankton, and these $\delta^{13} \mathrm{C}$ values are conserved up the food chain, the $\delta^{13} \mathrm{C}$ of aquatic consumers can provide information regarding energy sources for consumers at higher trophic levels (Vander Zanden and Rasmussen, 1999). Littoral, pelagic and benthic food webs can also differ in their carbon isotope ratios within a single water body (Post, 2002). Once a baseline is established, it is then possible to look for a relative difference in isotope ratios amongst organic samples (Post, 2002). Isotopes can accumulate in greater ratios in some organisms depending on their position within a food web. For example, predators higher in the food chain have a relatively higher $\delta^{15} \mathrm{~N}$ because they consume more animal matter that is rich in this isotope compared to ${ }^{14} \mathrm{~N}$ (Cabana and Rasmussan, 1994). In addition to examining naturallyoccurring variation, stable isotopes can be added into a system to create a labelling effect, which 
can then be traced through food webs (Grey, 2006). This particular usage is valuable in in examining how a target organism may interact with its surrounding community.

\section{Thesis aims}

It is clear that the influences of trematode cercariae within aquatic ecosystems have yet to be fully realized and understood. To effectively incorporate such free-living parasite stages into aquatic food webs, it is necessary to determine the extent of their consumption and how this may affect other members of aquatic communities. The purpose of my thesis research was thus to examine how consumption of the free-living cercarial phase of the trematode life cycle may affect freshwater food webs by focusing on alterations of predatory-prey dynamics, as well as the potential contribution of cercariae to carbon cycling.

In Chapter 2, I investigated whether the presence of cercariae as alternate prey for dragonfly larvae influenced zooplankton population dynamics. I hypothesized that the presence of cercariae as prey would have a direct and beneficial impact on Daphnia population numbers.

In Chapter 3, I determined the extent to which cercariae are consumed by select common invertebrates representing different trophic levels within ponds by employing experimental mesocosms and ${ }^{13} \mathrm{C}$-labeled cercariae. My prediction was that carbon derived from cercariae would be found in the greatest abundance in predators known to consume live cercariae.

This research will help us to better understand how cercariae interact with other freeliving members of freshwater communities, especially their potential impacts on sympatric zooplankton. This research also serves as a proof of concept test for the use of stable isotope labelling in tracking the consumption of cercariae by predators and other consumers. Given the ubiquity of trematode parasites in both freshwater and marine ecosystems, SIA could help to 
discover new trophic linkages and aid in restructuring food webs to include free living cercariae as important prey. 


\title{
Chapter 2: The beneficial impact of trematode infectious stages on zooplankton populations in the presence of predators
}

\begin{abstract}
Motile trematode cercariae represent a large amount of biomass in aquatic ecosystems, yet their interactions with other surrounding planktonic fauna are relatively obscure. Previous studies have shown that cercariae are consumed by many aquatic predators, including various larval insects, sometimes even preferentially so relative to other prey such as zooplankton. By serving as alternate prey, cercariae may thus decrease predation pressure on free-living animals with a similar trophic niche. The purpose of the current study was to examine the extent to which the presence of cercariae (Plagiorchis sp.) affected the population dynamics of common freshwater zooplankton (Daphnia sp.) in the presence of larval odonate predators known to consume both of these prey items. We used four treatments (12 replicates each) representing a factorial combination of infected or uninfected snails and the absence/presence of dragonfly larvae after seeding 48 mesocosms with starting populations of Daphnia. Weekly nondestructive samples of Daphnia were subsequently taken from each mesocosm over a four-week period to monitor their population size. Overall, there was trend for larger Daphnia populations in treatments containing Plagiorchis sp.-infected snails in comparison to those with uninfected snails. However, there was a highly significant interaction between the presence of infected snails and larval dragonfly predators for Daphnia population size. When faced with predation pressure, Daphnia reached higher numbers if accompanied by infected versus uninfected snails, suggesting a protective effect by cercariae that serve as alternate prey. Within natural settings, abundant snail populations harboring trematode infections may prove advantageous for
\end{abstract}


zooplankton communities facing predation. Further studies will be needed to determine how this varies depending on the predator, trematode, and zooplankton taxa involved.

\section{Introduction}

Zooplankton form an important part of aquatic communities around the world. They comprise a diverse group of microorganisms roughly between 0.2 and $2000 \mu \mathrm{m}$ in size (Maloney and Field, 1991; Hansen and Bjørnson, 1997) that include protozoans, rotifers, and several small crustaceans such as cladocerans, copepods and amphipods (Pace and Orcutt, 1981; Schriver et al., 1995). Across freshwater and marine ecosystems, zooplankton act as primary consumers that generally graze on phytoplankton and particulate organic matter (Hansen and Bjørnsen, 1997; Calbot and Landry, 2004), regulating the former (Carpenter et al., 1985; Brett and Goldman, 1997). Zooplankton have many important roles owing to their biomass and ecology (Hanson and Peters, 1984; Culver et al., 1985). Given their abundance, zooplankton also represent large sources of carbon, nitrogen and phosphorous within aquatic food webs (Andersen and Hessen, 1991), serving as critical prey items for many secondary consumers (Lynch, 1979). For instance, zooplankton are key sources of essential fatty acids for vertebrates, an important group of nutrients that impact reproduction and growth (Kainz et al., 2004). They additionally play an important role in recycling phosphorous in the ecosystem, acting as phosphorous sinks that mobilize phosphorous for higher trophic levels (Schindler et al., 1993). Healthy zooplankton communities may also offer protection against invasion by non-native zooplankton species to prevent them from becoming established and disrupting food webs (Dzialowski, 2007). Given these critical functions of zooplankton, it is important to understand various factors regulating their abundance and community composition. 
It has been well-established that freshwater zooplankton populations can be regulated by a trophic cascade model, i.e. influenced by organisms at higher trophic levels (Carpenter et al., 1985; Brett et al., 1997). Members of the genus Daphnia are crustaceans in the order Cladocera that are an important component of freshwater zooplanktonic communities and well-known to researchers. For instance, Daphnia contain large quantities of fatty acids that make them attractive prey to various fish and invertebrates (Brett et al., 2006). In temperate climates, Daphnia populations are moderated by both season and predation (Wu and Culver, 1994). Daphnia populations spike during spring and early summer, and then diminish until in some systems they become completely absent by fall (Wu and Culver, 1994). Predators such as pelagic fish and invertebrates drive Daphnia population sizes down by consuming mature individuals, while phytoplankton availability limits their growth as well (Wu and Culver, 1994; Gliwicz and Pijanowska, 1989).

To avoid pelagic predators such as fish, Daphnia undergo a vertical migration that moves them into the benthic zone, which is a prime feeding area for dragonfly larvae and other invertebrates that also prey upon these cladocerans (Burks et al., 2001). Larval odonates (dragonflies and damselflies) are voracious consumers of zooplankton, including Daphnia, consuming as many as $20-30$ individuals over the span of an hour in some cases (Hunt and Swift, 2010). However, predation upon Daphnia is influenced by various factors including the availability of alternative prey (Akre and Johnson, 1979). Predators may have various criteria driving their choice of prey, which can lead to altered interactions among prey species if one is favored over another (Akre, and Johnson, 1979). The presence of relatively vulnerable prey, such as those lacking defenses or high mobility, can particularly impact predation on co-occurring 
prey species simply by providing an easier option in terms of detection, capture, and consumption (Jeffries, 1988).

The presence of alternative prey may thus play an important role in predator-mediated population regulation for zooplankton such as Daphnia; however, the definition of zooplankton has been traditionally restricted to free-living animals, excluding other organisms that may contribute significant biomass (Morley, 2012). However, the life cycles of many macroparasites such as helminths include one or more stages that are free-living in the environment. For example, the free-living phase of trematode parasites (Phylum Platyhelminthes) known as cercariae enter into aquatic environments as non-feeding, short-lived zooplankton (Morley, 2012). Aquatic snails are a common first intermediate host for many trematodes, wherein they form rediae that produce cercariae through asexual reproduction (Morley, 2012). When mature, the motile cercariae emerge from the snail host and then swim through the water column in search of a second intermediate host to infect (Esch et al., 2002). In doing so, they join the zooplankton community as they are roughly equivalent the size range $(<2 \mathrm{~mm})$ that encompasses many zooplanktonic animals (Morley, 2012). Since most of these cercariae will ultimately not infect the next host in their life cycle, they could be important as prey items (Morley, 2012). This is especially so considering their sheer biomass within freshwater systems, including the calculation that a temperate freshwater pond may have annual cercariae biomass production equivalent to that of an Asian elephant (Soldànovà et al., 2016).

Various aquatic animals have now been demonstrated as predators of cercariae, including fish and insects (Orlofske et al., 2015; Rohr et al., 2015). Dragonfly larvae are known to be consumers of both Daphnia and cercariae (Schotthoefer et al., 2007; Orlofske et al., 2015). They may even preferentially feed on cercariae when given the choice of both prey items, primarily 
owing to the size of the larva; smaller dragonfly larva will consume cercariae more often, while larger ones prefer Daphnia (Catania et al., 2016). Such predation upon cercariae may have various consequences. The consumption of free-living cercariae has been noted to reduce infection of "downstream" hosts such as larval amphibians (Orlofske et al., 2012), but the impact of cercariae as alternate prey within zooplankton communities has received little attention (Morley, 2012).

Here, I sought to determine how the presence of cercariae may affect the abundance of another zooplanktonic animal, Daphnia, in the presence or absence of a predator represented by larvae of the dragonfly Leucorrhinia intacta. I hypothesized that experimental Daphnia populations would achieve higher numbers in the presence of cercariae when predators were present if these parasites served as alternative prey and reduced predation pressure on Daphnia.

\section{Materials and Methods}

\section{Experimental Design and Procedure}

A total of 48 plastic bins ( $40 \mathrm{~L}$ capacity) were set up in a $6 \times 8$ grid pattern outdoors at the Koffler Scientific Reserve in Newmarket, Ontario. Each bin was filled with approximately $20 \mathrm{~L}$ of water from an adjacent pond that was filtered through a screen $(\sim 1 \mathrm{~mm}$ mesh size) to allow for phytoplankton inoculation. The bins were separated into 4 treatments, with 12 bins randomly assigned to each: Daphnia only (A), Daphnia + predators (B), Daphnia + cercariae (C), Daphnia

+ predators + cercariae (D). I obtained zooplankton from the same pond by dipping plankton nets into the pond and emptying the entire quantity of captured zooplankton into the same container. From this single large container of zooplankton, I agitated and removed $500 \mathrm{~mL}$ aliquots using zooplankton nets. Although the aliquots did not exclusively contain Daphnia, these predominated. I then added a $500 \mathrm{~mL}$ aliquot of this zooplankton mixture to each of the 48 bins 
but kept 4 aliquots for quantification of the inoculation in the lab under a microscope. Based on this, each aliquot contained an average of 3066 individuals ( \pm 896 S.D.) of Daphnia sp. While the aliquots were not homogenous, other zooplankton species were not quantified. I also did not identify which specific species of Daphnia were present, but D. pulex tends to dominate in this particular pond (S. McCauley, University of Toronto; Pers. Comm.). Each bin had window screening mesh clipped over top of the opening to prevent colonization by other organisms. Data loggers (Hobo ${ }^{\circledR}$ mini-pendant) that recorded temperature and light intensity were placed in $50 \%$ of the bins, with 6 loggers per treatment.

All treatments received three snails (Stagnicola elodes) collected from a field site in Waterloo, Ontario (N43.476450, W80.554990). These were contained in mesh cylinders (15.2 x $14 \mathrm{~cm}$ ) that rested at the bottom of each bin to prevent their escape (Figure 2-1), but the mesh size $(0.32 \mathrm{~cm})$ was sufficient to easily allow passage by cercariae and has been successfully used in other studies (e.g., Koprivnikar et al., 2018). This ensured that the treatments requiring cercariae $(\mathrm{C}+\mathrm{D})$ had a constant influx present in the form of infected snails; treatments not requiring cercariae $(\mathrm{A}+\mathrm{B})$ had uninfected snails added to account for any possible effect of snail presence irrespective of parasites. All snails were screened prior to use to ensure the presence/absence of infection, as well as to guarantee that all cercariae emerging were of the same species/type. After their collection, the snails were held in the lab within aerated bins containing dechlorinated water, with regular feedings of spinach until the field experiment was set up. In order to screen snails for trematode infection, I followed established procedures (Szuroczki and Richardson, 2009). Briefly, they were placed in individual $10 \mathrm{~mL}$ wells of tissue culture plates filled with fresh, dechlorinated water and placed under incandescent lamps for a minimum of one hour. Each well was subsequently inspected for emerged cercariae using a 
dissection microscope and snails were sorted into new bins based on their type of infection (trematode species or uninfected). 


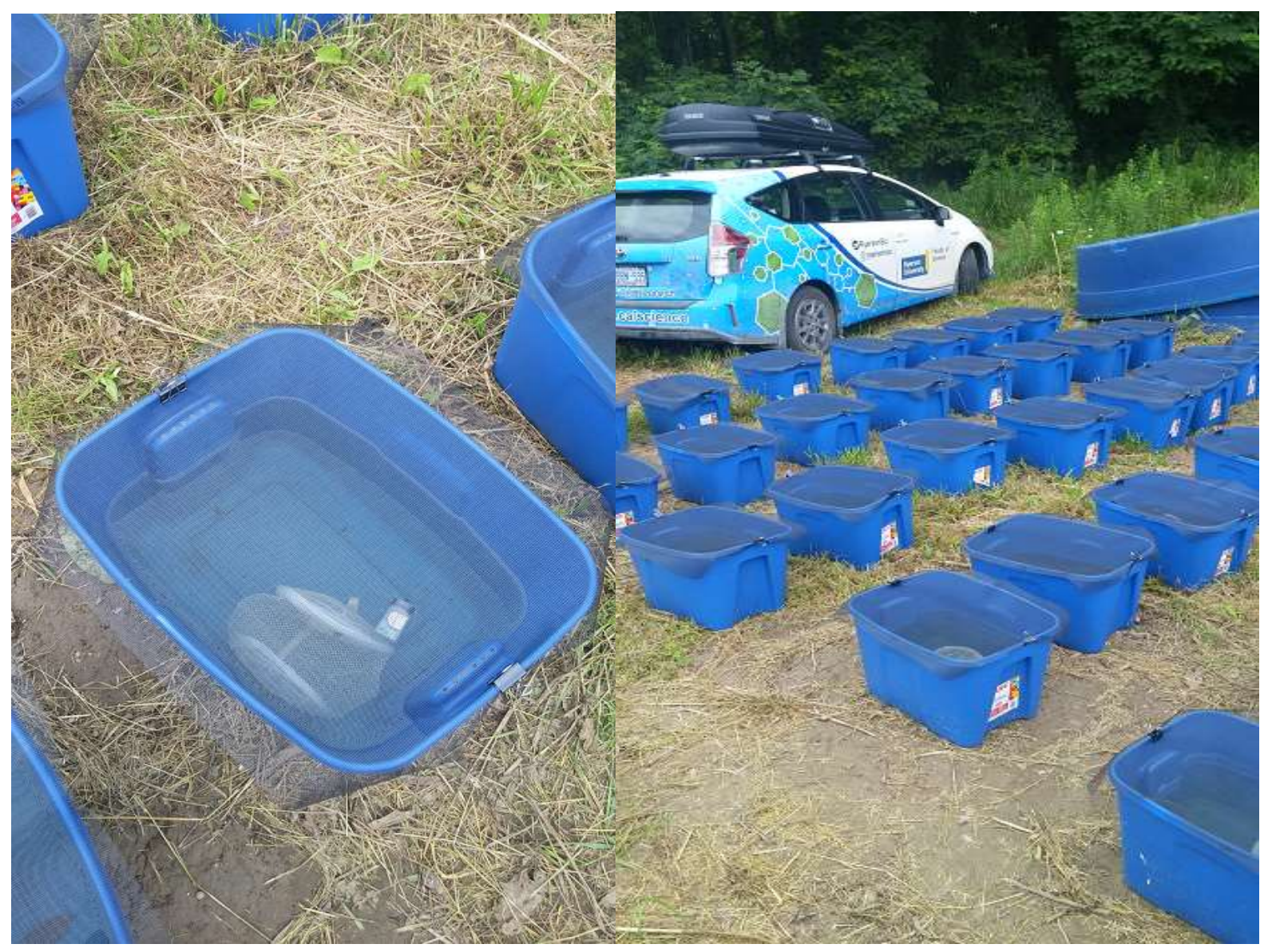

Figure 2-1: Experimental set-up including the overall layout of bins as well as an individual bin including the window screening mesh, mesh snail bag, and data logger. 
Cercariae can be identified by features of their external morphology, and I found many snails to be infected with a species within the family Plagiorchiidae using a standard guide (Schell, 1985). Lymnaeid snails serve as first intermediate hosts, and are prone to infection by plagiorchid trematodes, especially larger individuals (Yoder and Coggins, 1998). The cercariae produced are generally about $350 \mu \mathrm{m}$ in length (Faltýnková, 2005). The mesh bags containing infected snails were cycled through different bins within treatments C and D each week to try and account for random confounding factors such as variable cercariae production and emergence, as has been done with similar experiments employing mesocosms (Rohr et al., 2015). Although species within the family Plagiorchiidae typically encyst within various aquatic insects as second intermediate hosts, including larval odonates, a wide range of host taxa are used, and many of the trematode species show high specificity (Blankespoor, 1971). Based on experimental exposures conducted in the lab, I was able to confirm that the cercariae that I used here did not infect the larval odonates employed as predators.

To each treatment requiring predators (B and D), two dragonfly larvae (Leucorrhinia intacta) of roughly the same size were added. These were collected from two ponds within the KSR. This species of larval dragonfly in particular has been shown to not only consume, but preferentially choose cercariae as food based on their head-widths (Catania et al., 2016). The experiment ran for four weeks over July and August 2017 with non-destructive data collection (see below) occurring each Thursday. At the end of the experiment, snails were collected from each bin and measured for shell length, with dead snails accounted for. All snails were then frozen so that those designated as uninfected and used in treatments A and B could later be dissected and confirm their infection status to ensure that no cercariae could have emerged. 
Larval odonates were also gathered from each bin to measure their head width and account for predator mortality.

\section{Data Collection}

On the Thursday of each week during the experiment, strained zooplankton samples were taken from each bin to determine the abundance of Daphnia present. To do this, each bin was agitated through stirring with the handle of a plastic net to achieve a uniform distribution through the water column. Two litres of water were measured out using marked jugs and poured through a mesh strainer to condense the sample volume into a $100 \mathrm{~mL}$ cup. Each sample cup was sealed, labelled, and placed in a cooler to avoid overheating. The samples were transported to an on-site lab where the contents of each were viewed under dissection scope in a deep Petri dish to count adult Daphnia present; juveniles were not counted due to the tendency of adult Daphnia to drive population growth (Hülsmann and Weiler, 2000). As each Daphnia was counted, it was removed via a dropper and placed back into its respective sample cup. After all counting was complete, the samples were taken back to the bins corresponding to their labels and poured in. Through this procedure, I was able to avoid affecting abundance levels by the process of removing and counting the Daphnia. Based on the counts from the condensed $100 \mathrm{~mL}$ samples, I was then able to estimate the number of Daphnia/L in each bin.

\section{Statistical analysis}

Independent sample t-tests were first conducted to determine whether conditions differed between the bins corresponding to treatments with $(\mathrm{C}$ and $\mathrm{D})$ or without parasites $(\mathrm{A}$ and $\mathrm{B})$ in a way that may have confounded the influence of cercariae presence. I thus determined if there was a difference for the following aspects: proportion of snails alive in each bin at the end of the experiment, mean snail size in each bin, proportion of predators alive in each bin at the end of 
the experiment, mean predator size (head width) in each bin, mean temperature in each bin over the 4 week experiment, mean light level (in lux) in each bin over the 4 week experiment. Note that light and temperature data were only available for half of the experimental bins (see experimental procedure above). I then conducted another series of t-tests to look for differences in the same measures (excluding those related to predators) in bins corresponding to the absence (A and C) or presence (B and D) of predatory larval odonates. As there were no significant differences (see Results), I did not include aspects as covariates or random effects in my model examining the effects of cercariae and predator presence on Daphnia abundance.

To evaluate the effects of predators and cercariae on Daphnia abundance, I conducted a repeated-measures ANOVA utilizing a generalized linear model (GLM) procedure. The Daphnia count data was log-transformed after adding a value of 1 to account for zeroes so as to meet the assumptions of a normality. I used the week corresponding to each count as the within-subjects factor (i.e. time), and the categorical fixed effects of predator and parasite (presence or absence for both), as well as their interaction with each other and time. All analyses were conducted in SPSS (Vers. 24.0).

\section{Results}

The independent samples t-tests indicated no difference between bins with cercariae present or absent in their mean snail or predator size, proportion of predators alive the end of the experiment, and mean temperature or light readings. However, there was a significant difference in snail mortality $(\mathrm{t}=2.434, \mathrm{df}=46, \mathrm{P}=0.019)$ as this was higher for infected snails. As this was confounded with the fixed effect of cercariae presence in the GLM, it was not included as a random effect. There were no significant differences between bins with predators absent or present for any of these factors. Overall, Daphnia abundance increased through time (Wilks $\lambda=$ 
$0.152, \mathrm{~F}_{3,42}=78.317, \mathrm{P}<0.001$ ), indicating population growth (Figure 2-2). Abundance was significantly affected by the presence of predators alone $\left(\mathrm{F}_{1,44}=5.509, \mathrm{P}=0.023\right)$ as there were fewer Daphnia counted in bins with larval odonates present (Figure 2-3). There was also marginally insignificant positive effect of having cercariae present on Daphnia abundance $\left(\mathrm{F}_{1,44}\right.$ $=3.154, \mathrm{P}=0.083$; Figure 2-4). However, there was a strong and significant interaction between the presence of cercariae and dragonfly predators on Daphnia abundance $\left(\mathrm{F}_{1,44}=7.295, \mathrm{P}=\right.$ 0.010). Although Daphnia numbers were reduced in the bins containing predators relative to those without, their abundance when both larval odonates and cercariae were present was similar to that in bins with no predators (Figure 2-5). 


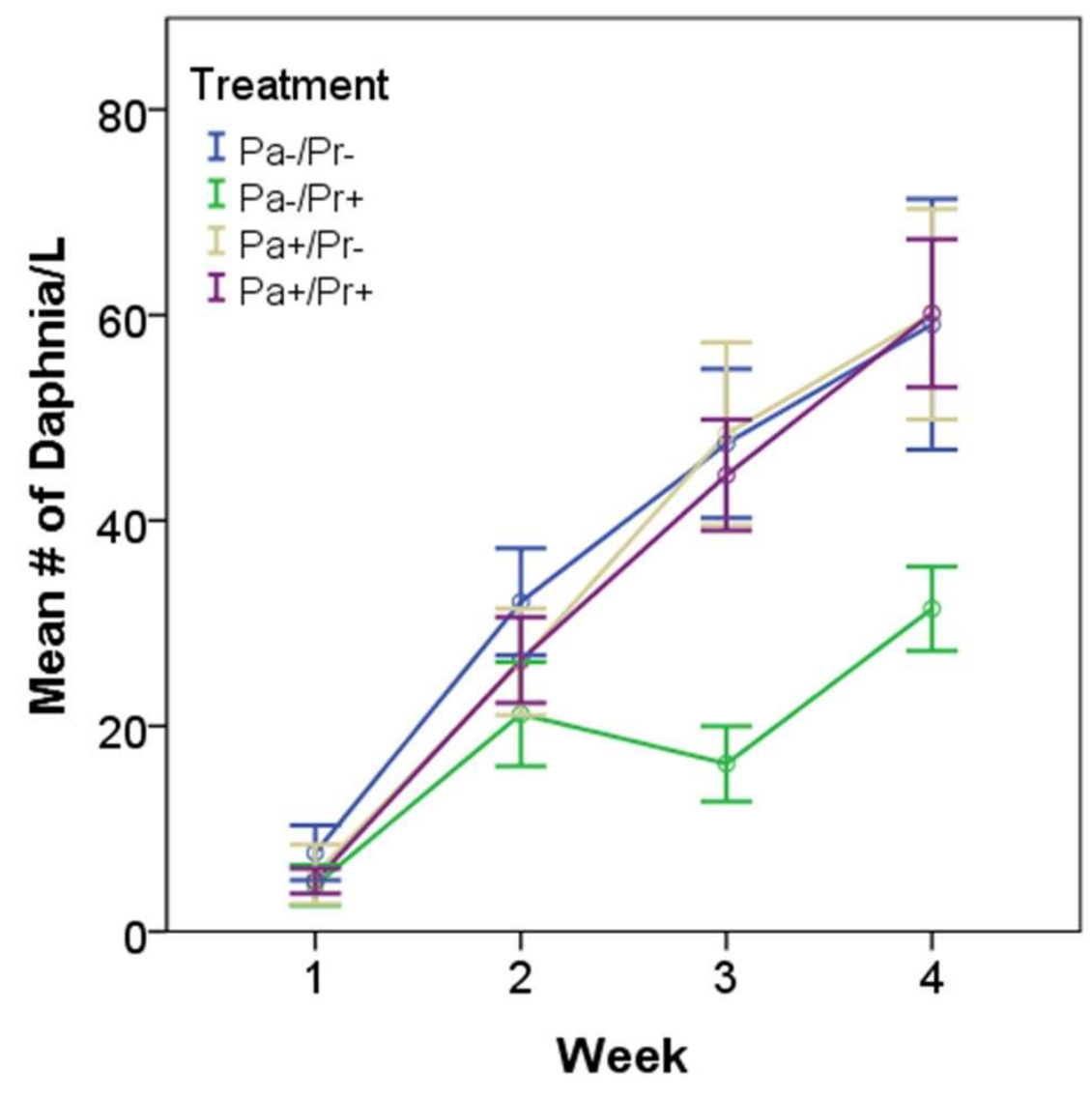

Figure 2-2: Mean number of Daphnia over 4 weeks $( \pm$ S.E. $)$ across all treatments with trematode parasite cercariae $(\mathrm{Pa})$ and larval odonate predators $(\mathrm{Pr})$ either present $(+)$ or absent $(-)$. 


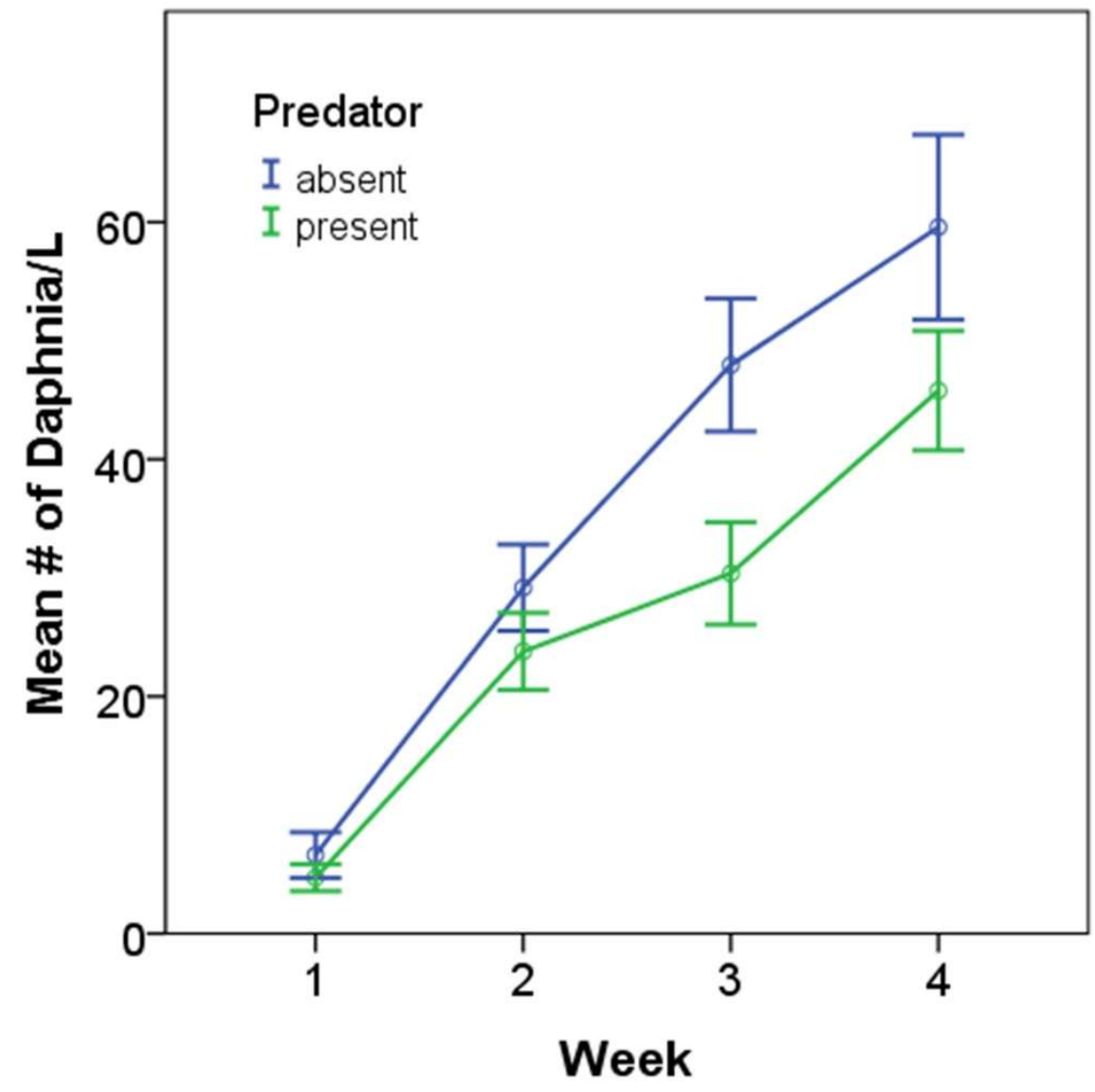

Figure 2-3: Mean number of Daphnia ( \pm S.E.) over time with larval odonate predators absent (blue) or present (green). 


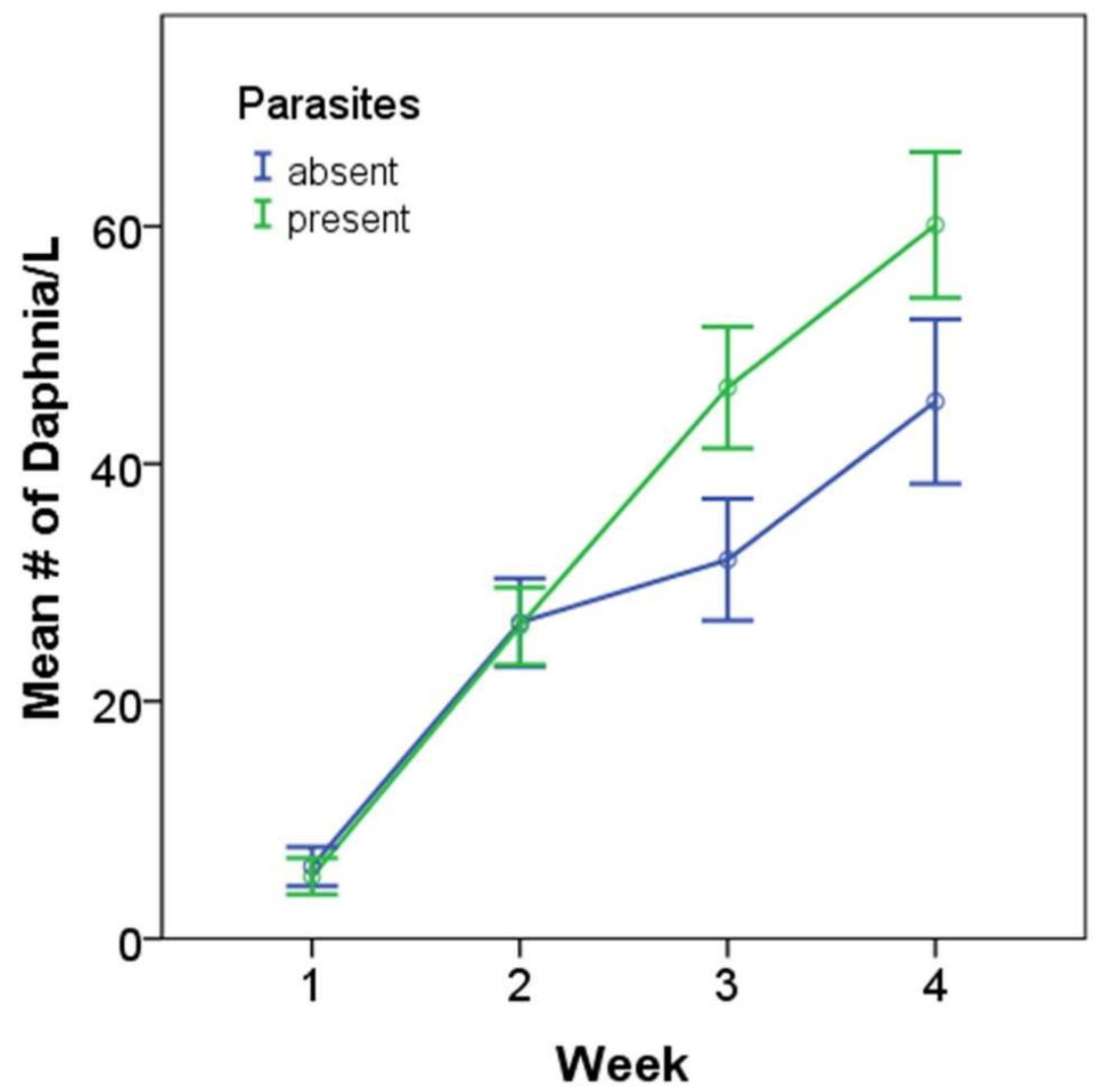

Figure 2-4: Mean number of Daphnia ( \pm S.E.) over time with cercariae of trematode parasites absent (blue) or present (green). 


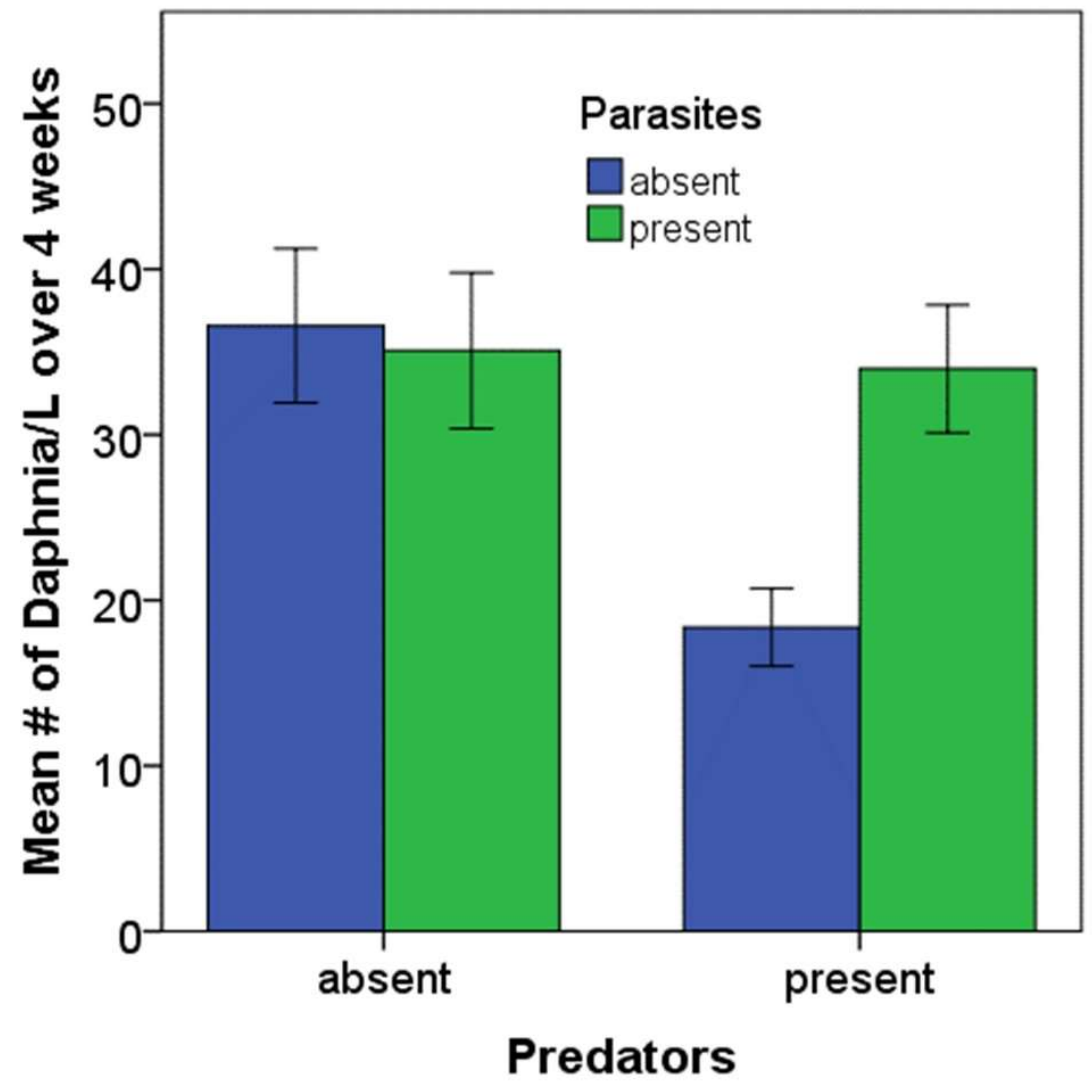

Figure 2-5: Mean number of Daphnia ( \pm S.E.) over time with cercariae of trematode parasites absent (blue) or present (green), as well as the presence or absence of larval odonate predators. 


\section{Discussion:}

The presence of cercariae had a strong positive impact on the population abundance of Daphnia when there were larval dragonfly predators present as well. Daphnia abundance was positively affected by cercarial presence even without predators, suggestive a possible benefit outside of the latter serving as alternative prey. As Daphnia have been reported to consume other small-bodied cercariae as well, the cercariae used here could have been a supplementary food item for them (Christensen, 2009). This being said, given that the larval odonate L. intacta is a known consumer of both prey items utilized in my study (Catania et al., 2016), my results suggest that the presence of cercariae likely benefits Daphnia populations by relieving predation pressure on these zooplankton. This represents an important aspect related to predation on cercariae that has been overlooked as this consumption has been typically viewed from the perspective of impacts on transmission to second intermediate hosts (Orlofske et al., 2012; Thieltges et al., 2013), not how this may affect the contemporary zooplankton.

When evaluating the potential for cercariae to relieve predation pressure upon zooplankton such as Daphnia in nature, it is necessary to consider their spatial and temporal overlap. Diel vertical migration is a common strategy used by zooplankton to avoid predators (Hays, 2002). Daphnia tend to avoid daytime pelagic predators by receding into deeper areas in their aquatic habitat, while returning to shallower depths at night (Hays, 2002). Trematodeinfected snails tend to occupy the benthic littoral zones of their ecosystems (Thieltges et al., 2008), thus cercariae may be found in high density close by considering that they tend to emerge in large masses (Haas, 1994). However, cercariae can exhibit a plethora of spatially-related behaviours, including swimming towards chemical stimuli indicating host presence, and especially geo- and photo-taxis to facilitate overlap with the next host in their life cycle, and can 
disperse away from their snail hosts (Haas, 1994). Given that cercariae emergence for most temperate species occurs at greater rates during the warm daylight hours during summer (Lo and Lee, 1996), and Daphnia migrate to greater depths during the same time period, it is likely that both spatial and temporal overlap occurs between the two taxa. This creates a potential for interaction between the two entities that may relieve predation pressure upon zooplankton, and may include the possibility of consumption of cercariae by Daphnia, as well as mechanical disruption of cercarial movement by zooplankton that could affect transmission (Christensen, 2009).

Weekly sampling of Daphnia showed that the zooplankton communities within each bin were not homogenous. Several other zooplanktonic taxa were present, including amphipods and copepods. There is thus potential for these animals to have also been predated upon by larval dragonflies, which could have had an influence on abundance; however, it was expected that this effect was evenly distributed across all bins and treatments. Whether this beneficial influence of cercariae on Daphnia will occur as strongly in nature is not clear. For example, bias may have been introduced when collecting larval dragonflies; since larger dragonfly larvae ( $>3.5 \mathrm{~mm})$ will preferentially consume larger prey such as Daphnia (Catania et al., 2016), it is possible that the larvae used here selectively fed on Daphnia due to their size $(\overline{\mathrm{x}}=5.1 \mathrm{~mm}$, S.D. $=0.5 \mathrm{~mm})$, but the positive interaction between predator and cercariae presence suggests consumption of both prey. Consequently, the presence of only very large larval dragonflies may provide little benefit of cercariae presence to zooplankton. Considering that the mortality of infected snails was higher than uninfected, the dead snail matter may have broken down and provided nutrients that promoted algae growth, which may have provided greater food availability for Daphnia in those 
treatments. However, this should have been mitigated by the cycling of mesh snail holding bags among bins assigned infected snails.

Future studies could further attempt to isolate the Daphnia and cercariae by removing predators and other zooplanktonic organisms to determine if there is an interaction between the two in terms of feeding or otherwise that may explain the benefit of cercariae to these cladocerans. Combinations of cercariae from different species of trematode should also be tested considering their diversity in size and morphology (Chapter 1), as well as different known and assumed predators of both Daphnia and cercariae, to understand the possible extent of this positive effect of cercariae presence in diverse aquatic ecosystems. 


\title{
Chapter 3: The contribution of trematode cercariae to carbon cycling in freshwater habitats.
}

\begin{abstract}
Free-living trematode cercariae remain understudied members of aquatic ecosystems, though more literature is shedding light on their enigmatic role as prey organisms. Previous studies have shown several aquatic predators, including fish, insects, and planktonic crustaceans consume cercariae, but the ultimate fate of cercariae that do not infect hosts remains unclear. Having an estimated biomass that is larger than several free-living contemporary aquatic insect orders such as the beetles (coleoptera) and dragonflies (Odonata), cercariae represent a large potential source of nutrient. Few studies have utilized isotope analysis when directly dealing with cercariae, and none have use stable isotope analysis to track cercarial biomass in food webs. The stable isotope of carbon, ${ }^{13} \mathrm{C}$, is a safe and efficient labelling agent that has been used in many food web studies. Through this study, it was determined that cercariae of the genus Plagiorchis can be effectively labelled with ${ }^{13} \mathrm{C}$ when introduced through food to their snail host. A novel food web containing diving beetles (Dytiscidae sp.), dragonfly larvae (Leucorrhinia intacta), oligochaete worms and a zooplankton community was housed in large mesocosm containers in an outdoor setting, with ${ }^{13} \mathrm{C}$ labelled cercariae being added as food. Oligochaete worms were found to have elevated levels of ${ }^{13} \mathrm{C}$, suggesting benthic detritovores are important consumers of cercarial biomass. Given the large quantity of cercariae in natural settings, a more profound effect may be witnessed if cercariae are added at higher densities. Many studies linking the trophic importance of cercariae could make effective use of this method in the future.
\end{abstract}




\section{Introduction}

Parasites are known to have impacts on food web structure and dynamics (Hatcher et al., 2006; Lafferty et al., 2008), often by affecting host fitness and predator-prey dynamics (see Chapter 1). By reducing host fitness and survival, parasites may reduce prey availability, also negatively affecting the predators reliant on them (Hatcher et al., 2006). Alternatively, predators may also benefit from prey that become infected, especially as a host may modify its behaviour, or have its behaviour modified, in ways that increase its likelihood of being consumed (Lafferty and Morris, 2006). However, the study of parasites as independent prey in themselves is a relatively new topic even though this phenomenon may be fairly common (Thieltges et al., 2013). There are many ways in which a parasite could become prey, such as through concomitant predation when a parasitized host is eaten by a predator, or when an animal grooms itself, often consuming ectoparasites (Johnson et al., 2010). In addition, parasites with free-living phases, like the motile cercariae of trematode (flatworm) parasites, can become prey in their own right (Johnson et al., 2010). With the recognition that parasites are likely be involved in food webs as prey, those parasites with complex life cycles involving free-living stages, such as trematodes, have been demonstrated to increase food web complexity owing the number of linkages in which they take part (Thieltges et al., 2013).

When cercariae emerge from their first intermediate hosts, typically aquatic gastropods, they join the zooplankton community in the water column and passively or actively remain suspended by swimming until they locate a host (Morley, 2012). During this phase, which may last only a few hours considering their short lifespans (often $<24$ hours), they are at risk of being eaten by various predators owing to their similarity in size to many zooplankton and their lack of any defences (Morley, 2012). Given the vast quantity of cercariae that may emerge from a single 
snail per day, as many as 500,000 in exceptional cases for some trematode species (Morley, 2012), this could represent a large source of prey for aquatic predators. These pulses of cercariae represent huge amounts of biomass (see Chapter 1). Considering that a diverse array of predators has been shown or suggested to consume cercariae (Orlofske et al., 2015; Rohr et al., 2015; see Chapter 1), this may be beneficial to potential hosts downstream in the life cycle by reducing parasite transmission (Schotthoefer et al., 2007; Thieltges et al., 2013).

As a consequence, a substantial proportion of cercarial biomass never actually ends up within successfully infected hosts, and is instead predated upon or dies (Schotthoefer et al., 2007). Although predation upon live cercariae has now been reported for a variety of trematode and predator species (see Chapter 1), it is likely that many cercariae will die and join other organic detritus, and thus a considerable amount of their biomass may actually be consumed by benthic detritivores. For instance, common detritivores such as oligochaete worms could serve as potential consumers of cercariae biomass. Terrestrial annelids, particularly earthworms, have been shown to accidentally consume parasites while feeding (Johnson et al., 2010), which benthic oligochaetes may parallel. In addition, a commensal oligochaete (Chaetogaster limnaei limnaei) of aquatic mollusks consumes large quantities of cercariae, rapidly increasing its population size by doing so (Hopkins et al., 2013).

Given the substantial biomass of cercariae calculated for freshwater ponds (Preston et al., 2013; Soldànovà et al., 2016), it is important to identify the ways in which they may be contributing to energy flow and nutrient cycling by considering various trophic levels. However, studies of cercariae consumption to date have largely focused on only a few predators (see Chapter 1). In the absence of fish, diving beetles can be considered among the top predators of their freshwater ecosystems (Cobbaert et al., 2010). Within the context of consuming cercariae, 
diving beetles have been assumed, but not tested, to consume cercariae (Rohr et al., 2015).

Diving beetles are generalist pelagic predators, consuming zooplankton and macroinvertebrates alike, but it is likely that the easiest prey will be consumed preferentially (Cobbaert et al., 2010). Since cercariae lack any defences, they could thus be consumed if present in the vertical water column range of diving beetles.

A number of studies have shown dragonfly larvae to be successful predators of cercariae, with an important influence on parasite transmission (Schotthoeffer et al., 2007; Orlofske et al., 2015; Rohr et al., 2015), but these odonates may also play a role in accumulating and transferring cercariae-derived carbon and nitrogen. Dragonfly larvae have even been shown to preferentially consume cercariae based on larval size in accordance with optimal foraging theory (Catania et al., 2016). For young odonate larvae, cercariae could potentially be an important source of nutrients and energy until growth allows them to efficiently consume other prey (Catania et al., 2016).

A variety of freshwater zooplankton, including crustaceans such as Daphnia, copepods, and ostracods, have been shown to influence trematode transmission through predation upon cercariae (Christensen, 2009). Some studies have suggested, but did not observe, consumption of cercariae by other common zooplankton such as amphipods (Rohr et al., 2015). Determining which aquatic fauna may consume cercariae has thus far been limited partially by the methods employed. Notably, tracking and identifying the consumption of cercariae has thus far relied on lab-based feeding trials with mechanical observation and counting over relatively short periods of time. Stable isotope labelling may therefore be a rigorous way to 'observe' consumption over time in more natural settings, as well as detect consumption by relatively cryptic potential consumers of cercariae biomass. 
Of the two naturally-occurring stable isotopes of carbon, ${ }^{13} \mathrm{C}$ is found as a small percentage of the overall ratio of carbon $\left(98.9^{12} \mathrm{C}\right.$ to $\left.1.1{ }^{13} \mathrm{C}\right)$ (Rounick and Winterbourn, 1986). This natural occurrence makes it convenient for use in labelling organic substances and tracing carbon pathways through the environment, as spikes in carbon isotope ratios beyond their background occurrence are easily identifiable (Post, 2002). It is also very useful for tracing carbon movement through trophic levels because consumers generally accumulate the full ${ }^{13} \mathrm{C}$ ratio found within their food sources rather then only a fraction of it (Finlay, 2001). As consumers integrate digested carbon into their own tissues, the new isotopic ratio within the organism will fraction and become apparent as growth occurs, which could take weeks to months depending on the organism (Finlay, 2001).

Food webs are a convenient conceptual paradigm to track how carbon moves through trophic levels (Gu et al., 1994). While organisms in higher trophic levels do not naturally have higher levels of ${ }^{13} \mathrm{C}$, their carbon isotope ratio can provide clues into the food items consumed if those ratios are known (Vander Zanden et al., 1999). Small organisms, such as cercariae, exhibit a tendency to negatively fraction stable isotopes from their source of consumption; that is, a cercaria should have a lower ratio of ${ }^{13} \mathrm{C} /{ }^{12} \mathrm{C}$ than its snail host (Dol et al., 2010). In order to adequately 'label' such an organism, its host would need to see a proportionally larger increase in ${ }^{13} \mathrm{C}$.

Here, I sought to determine whether cercariae could be labelled with ${ }^{13} \mathrm{C}$ and traced through a model food web within experimental mesocosms to determine where cercariae-derived carbon may end up within consumers representing different trophic levels of a freshwater ecosystem. Since an experiment of this type has not been previously performed to the best of my knowledge, this experiment served as a proof of concept for the efficacy of carbon isotope 
labelling as a viable option for tracing cercarial carbon pathways, and therefore the potential energetic and nutrient contributions of cercariae biomass in ecosystems. I hypothesized that I would be able to discern heightened ratios of ${ }^{13} \mathrm{C}$ in organisms previously shown to consume cercariae, such as dragonfly larvae.

\section{Materials and Methods}

\section{Experimental Design}

Fourteen plastic mesocosms consisting of livestock watering tanks capable of holding 378 L each were set up outdoors at the Koffler Scientific Reserve (KSR) in Newmarket, ON. The mesocosms were separated into 3 treatments: treatment A received ${ }^{13} \mathrm{C}$ labelled cercariae (see labeling procedure described below), treatment $\mathrm{B}$ received unlabelled cercariae, and treatment $\mathrm{C}$ received a sham consisting of dechlorinated water in the same amount $(100 \mathrm{~mL})$ as that holding cercariae in the other 2 treatments. Treatment A had 10 replicates (mesocosms), with treatments $\mathrm{B}$ and $\mathrm{C}$ each having 2 replicates. This was done so as to maximize the sample size for tanks receiving ${ }^{13} \mathrm{C}$ labelled cercariae, thus increasing the chances of detecting spikes in $\delta^{13} \mathrm{C}$ from mesocosm fauna given that this approach had not been previously tested. Water from an adjacent pond was pumped through a $5 \mathrm{~mm}$ mesh filter into each mesocosm until they were filled roughly $2 / 3$ of their capacity to establish a natural community of phytoplankton and beneficial bacteria. To provide a substrate for benthic fauna, oak leaves were collected on site and added to each mesocosm to simulate sediment and provide a source of nutrients in keeping with standard mesocosm set-up procedures (Semlitsch et al., 2010). Plastic plants were added to act as cover, with weighted and floating plants used to stratify habitat within the water column.

To each mesocosm, I added the following to create a simple model freshwater food web: 3 diving beetles (family Dytiscidae), 3 dragonfly larvae (Leuchorrinia intacta), $0.5 \mathrm{~g}$ of 
oligochaete worms (Lumbriculus variegatus), and $1 \mathrm{~L}$ of zooplankton largely consisting of Daphnia (see animal collection below). With these select fauna, I included trophic levels that represented primary consumers (zooplankton), secondary consumers (diving beetles and dragonfly larvae), and benthic detritivores (oligochaetes). As detailed in the Introduction and elsewhere in this thesis (Chapter 1), dragonfly larvae are noted predators of cercariae, and some zooplankton may consume them as well. Floating data loggers (Hobo ${ }^{\circledR}$ Pendant) capable of recording temperature and light intensity were placed in each of the 14 mesocosms. Window screening mesh was clipped on top of the mesocosms in an attempt to exclude colonization by other organisms. Finally, treatments were randomly assigned to each mesocosm after set-up.

\section{Animal Collection}

I stocked the mesocosms with animals that were either ordered from biological supply companies or locally collected from ponds. Oligochaetes (L. variegatus) were obtained from Merlan Scientific and weighed into $0.5 \mathrm{~g}$ samples (wet mass) representing a number of individuals before they were added to each mesocosm. Dragonfly larvae (L. intacta) were collected from several ponds across southern Ontario via sweep nets, with primary collection occurring at the KSR. Identification occurred on site, and only larvae roughly 2-4 $\mathrm{cm}$ in body length were kept. I chose this size range because head width correlates with body width, which influences prey choice by larval dragonflies, and those used here are thus consistent with $L$. intacta sizes previously shown to consume cercariae (Catania et al., 2016). Diving beetles (family Dytiscidae) were also collected on site at the KSR through dip-netting near aquatic vegetation. Adults with a range of size between $2-6 \mathrm{~cm}$ in length were kept so as to ensure a standard size among mesocosms. Zooplankton, primarily containing Daphnia based on previous examination (see Chapter 2), were collected by fine mesh net at the KSR as well. These were 
pooled into a single large container of water and agitated such that each mesocosm received a 1 $\mathrm{L}$ aliquot, with 2 aliquots set aside for counting so as to estimate starting biomass. Only adult Daphnia were counted, with an average of $8040 \pm 565$ S.E. added to each mesocosm.

\section{Cercariae ${ }^{13}$ C Labeling}

Snails (Stagnicola elodes) were collected from the same pond and screened using the same methods as described in Chapter 2. For this experiment, only snails shedding cercariae within the family Plagiorchiidae were used. Plagiorchiid trematodes can use lymnaeid snails as a first intermediate host, producing cercariae that are roughly $350 \mu \mathrm{m}$ in length (Faltýnková, 2005) and often utilize aquatic insects (larval odonates, mosquitoes, caddisflies, and mayflies) or other snails as second intermediate hosts (Schell, 1985). I conducted infection trials in the lab with $L$. intacta (the most likely second intermediate host within my mesocosms) by introducing plagiorchiid cercariae into holding jars to ensure these would not encyst and cause infection. After confirming that these cercariae were not infective to L. intacta, all snails with confirmed infections were placed in $15 \mathrm{~L}$ holding bins filled with dechlorinated water, at a maximum of 30 individuals per bin and maintained in the lab at $\sim 24{ }^{\circ} \mathrm{C}$ under full-spectrum lighting on a $16: 8$ hour day/night cycle.

As I hypothesized that cercariae developing within the rediae that were consuming snail host tissue would incorporate ${ }^{13} \mathrm{C}$, it was necessary to inundate the snail body with this isotope. To do so, I made experimental snail food with the following recipe: $7.347 \mathrm{~g}$ of Nutrafin ${ }^{\circledR}$ dried fish flakes, $16.686 \mathrm{~g}$ of agar powder, $0.637 \mathrm{~g}$ of calcium carbonate, and $0.577 \mathrm{~g}$ of sodium carbonate $\left(\mathrm{NaH}^{13} \mathrm{CO}_{3}\right)$ containing $99 \%{ }^{13} \mathrm{C}$ (Sigma Aldrich, item \#372382). This represents $2.3 \%$ of sodium bicarbonate by weight. Given that such labeling of cercariae has not been previously attempted, I used previous experiments utilizing ${ }^{13} \mathrm{C}$ as a tracer in aquatic food web experiments 
as a rough guide. For example, Taipale et al., (2011) aimed for a target ${ }^{13} \mathrm{C}$ enrichment of $30 \%$ in cultures of freshwater algae with which to feed Daphnia, and replaced $3 \%$ of the $\mathrm{NaHCO}_{3}$ within their growth media with $\mathrm{NaH}^{13} \mathrm{CO}_{3}$ to do so. In another experiment that utilized ${ }^{13} \mathrm{C}$ labeled diatoms to investigate uptake by Arctic copepods, the medium in which the diatoms were cultured was enriched with $\mathrm{NaH}^{13} \mathrm{CO}_{3}$ at a concentration of $0.2 \mathrm{~g} / \mathrm{L}$ for $3-5$ days until they were found to be considerably enriched with ${ }^{13} \mathrm{C}$ (Graeve et al., 2005). My use of $2.3 \% \mathrm{NaH}^{13} \mathrm{CO}_{3}$ is thus within this range of enrichment. Such gelatinous food is commonly used for maintaining freshwater snails in the lab (Johnson and Hartson, 2009). The food was formed into gelatinous cubes by adding the ingredients above into $160 \mathrm{~mL}$ of tap water, heating and stirring this mixture in a beaker until it formed a paste, pouring it into ice cube trays with $1 \mathrm{~cm}^{3}$ cells, and placing these in a freezer at $-20{ }^{\circ} \mathrm{C}$ until use. Snails in each of the communal housing bins were fed 4 cubes twice per week. However, I also maintained a separate group of infected snails that provided the unlabeled cercariae needed for addition to the two tanks assignment to treatment B. These were housed separately and fed cubes of the same recipe described above except that they lacked any sodium carbonate and instead had the amount of calcium carbonate increased to compensate for total mass. Feeding of these experimental diets began 2 weeks before the mesocosms were set up. Snails that died during the experiment were replaced by others also infected by same trematode and preserved by freezing for later stable isotope analysis.

Each week, cercariae were shed using a standard approach (see Chapter 2) from all infected snails for addition to mesocosms based on their treatment. Snails were not added directly to the mesocosms to avoid any unwanted introduction of ${ }^{13} \mathrm{C}$ via feces or death and consumption of snail biomass. A ratio of 3:1 labelled to unlabeled snails were shed to ensure similar numbers of cercariae were added to mesocosms in treatments A and B. This worked out 
to an average of 30 labelled and 10 unlabelled snails that were shed each week. The cercariae were pooled into 2 separate samples within containers holding $1600 \mathrm{~mL}$ or $400 \mathrm{~mL}$ of water for the labelled and unlabeled cercariae, respectively. The total volume for each separate pooled sample was then aliquoted into $100 \mathrm{~mL}$ sub-samples such that one of these was added to a single mesocosm, with two $100 \mathrm{~mL}$ samples kept to estimate the cercariae abundance in each weekly addition. Given the large variation in cercariae emergence among weeks, the mean $( \pm$ S.D. $)$ number added weekly was $105( \pm 90)$ for labelled cercariae and $145( \pm 118)$ for unlabelled cercariae. Two $100 \mathrm{~mL}$ samples of dechlorinated water were set aside to act as sham additions to the mesocosms assigned to treatment $\mathrm{C}$. The experiment ran for 4 weeks, with cercariae addition occurring once a week. After collecting cercariae in lab as described above, the $100 \mathrm{~mL}$ samples were transported in a cooler to the KSR, and each sample was poured into the appropriate mesocosm by spreading it across the surface to ensure an even distribution.

\section{Sample Collection and Analysis}

At the beginning of the fifth week of the experiment, I collected samples from the mesocosms so these could be utilized for stable isotope analysis (SIA) that would provide information regarding ${ }^{13} \mathrm{C} /{ }^{12} \mathrm{C}$ (i.e. $\delta^{13} \mathrm{C}$ ). Diving beetles and dragonfly larvae were collected by dipnet and put into separate labelled containers. The oak leaf sediment was collected onsite, placed into large buckets, and transported to the lab. I later sifted through these in the lab to collect oligochaetes that represented pooled samples from each mesocosm (individual worms do not provide sufficient biomass for SIA). The entire volume of water in each mesocosm was filtered onsite to capture as much zooplankton as possible. After agitation with a rod, I siphoned the water with a tube through a standard zooplankton net to reduce the water level, and then poured the remainder through the mesh by lifting each bin. Similar to the oligochaetes, 
zooplankton were pooled into single samples for each mesocosm. All samples were preserved via freezing in microcentrifuge tubes until preparation for SIA. I also dissected labelled and unlabeled snails to separate the head-foot region of the snail from rest of the body containing the trematode rediae. These were then pooled into 3 samples per foot or body sample, representing snails fed either labeled or unlabeled food (i.e. total $n=6$ ), and frozen as well. Lastly, I also froze 6 cubes that contained labeled sodium carbonate, and 6 that did not.

For SIA, all samples needed to be dehydrated prior to crushing into a powder. Samples were first weighed on a microbalance (Mettler Toledo model no. XP6) prior and then placed in a $-80^{\circ} \mathrm{C}$ freezer for one week to reduce their temperature and enhance dehydration. Each sample was then transferred into a cryovial and put in a freeze drier (Labconco model no. 7670520) for 4-5 days. After this step, the vials were capped and placed back into the $-80^{\circ} \mathrm{C}$ freezer until powdering. To powder, each sample was individually emptied into a mortar and flash frozen with liquid nitrogen to increase brittleness for ease of crushing with a pestle. After each sample was crushed, the mortar and pestle were cleaned using tap water and ethanol to ensure that no residue remained. In addition, the ${ }^{13} \mathrm{C}$ labelled samples were crushed using separate instruments from the unlabelled samples to reduce the chances of cross-contamination. Powder ranging 0.5-2 $\mathrm{g}$ in mass from each individual sample was then transferred into tin capsules and folded before arrangement into 96-well tissue culture plates in accordance with standard SIA sample preparation protocols. The samples were then sent to the Environmental Isotope Laboratory at the University of Waterloo in Waterloo, ON for SIA. 


\section{Statistical Analysis}

Mean values for the $\delta^{13} \mathrm{C}$ of each sample are provided in Table 3-1, along with sample sizes. I first used a Q-Q plot to determine if my data met the assumptions for a normal distribution. I then performed a univariate analysis of variance (ANOVA) using a generalized linear model (GLM) procedure followed by Tukey LSD posthoc tests. For this, I ran two separate analyses, with one only including the taxa that were considered mesocosm samples (i.e. no food or snail data), and the other with only lab samples (i.e. food and snail samples). For both, I entered label as a categorical fixed effect ( 0 for unlabelled and 1 for labelled samples), as well as the material type, and their interaction. For the mesocosm ANOVA, I did this by assigning each of the 4 taxa to a different category (oligochaetes $=1$, zooplankton $=2$, dragonfly larvae $=$ 3 , and diving beetles $=4$ ). For the lab ANOVA, I similarly assigned each material to a different category $($ food $=1$, snail foot $=2$, and snail rediae $=3$ ).

I then performed a series of one-sample t-tests for each material/taxon. This was done in order to compare the $\delta^{13} \mathrm{C}$ for each ${ }^{13} \mathrm{C}$ labelled material to a taxon (or material) specific baseline value represented by the mean of their unlabelled counterparts given that these showed inherent variation based on their trophic level. These one-sample t-tests thus served as an additional approach to determine if each material/taxon showed any significant level of ${ }^{13} \mathrm{C}$ labelling. This was particularly useful for the mesocosm samples as their numbers were uneven when broken down into labelled $(\mathrm{n}=57)$ versus unlabelled $(\mathrm{n}=28)$ based on my experimental design. As such, those taxa with large sample sizes (diving beetles and larval odonates relative to the pooled samples for oligochaetes and zooplankton) would disproportionately influence the results of the GLM above. All statistical analyses were performed using IBM SPSS (version 24.0). 
Table 3-1: Mean values of $\delta^{13} \mathrm{C}$ resulting from stable isotope analysis (SIA). Sample sizes (n) indicated as well. Note that ${ }^{12} \mathrm{C}$ is naturally more abundant than ${ }^{13} \mathrm{C}$, thus less negative values indicate samples that are isotopically heavier (i.e. higher $\delta^{13} \mathrm{C}$ ).

\begin{tabular}{|l|c|c|}
\hline \multicolumn{1}{|c|}{ Material } & Unlabeled (n) & ${ }^{13}$ C labeled (n) \\
\hline Food & $-21.34(4)^{*}$ & $421.78(6)$ \\
\hline Snail head/foot & $-22.62(3)$ & $-14.16(3)$ \\
\hline Snail body & $-23.53(3)$ & $-4.05(3)$ \\
\hline Zooplankton & $-29.06(4)$ & $-28.75(10)$ \\
\hline Oligochaetes & $-30.05(4)$ & $-25.55(9)$ \\
\hline Dragonfly larvae & $-28.50(9)$ & $-28.78(19)$ \\
\hline Diving beetles & $-30.20(11)$ & $-29.67(19)$ \\
\hline
\end{tabular}

*Two samples destroyed during SIA. 


\section{Results}

The GLM for the mesocosm samples showed a significant effect of ${ }^{13} \mathrm{C}$ labelling $\left(\mathrm{F}_{1,77}=\right.$ 13.027, $\mathrm{P}=0.001)$, taxon $\left(\mathrm{F}_{3,77}=7.482, \mathrm{P}<0.001\right)$, and a significant interaction of these two factors $\left(\mathrm{F}_{3,77}=8.037, \mathrm{P}<0.001\right)$. Overall, $\delta^{13} \mathrm{C}$ was higher in labelled samples than unlabelled (Fig. 3-1). Tukey LSD post-hoc tests showed that oligochaetes and diving beetles were significantly different in ${ }^{13} \mathrm{C}$ ratio from the other two taxa. The analysis for the lab materials also indicated a significant effect of ${ }^{13} \mathrm{C}$ labelling $\left(\mathrm{F}_{1,16}=1007.905, \mathrm{P}<0.001\right)$, as well as material type $\left(\mathrm{F}_{2,16}=992.167, \mathrm{P}<0.001\right)$, and a significant interaction of these two factors $\left(\mathrm{F}_{2,16}=\right.$ 976.428, $\mathrm{P}<0.001$ ). The snail food had the highest overall ${ }^{13} \mathrm{C}$ label (see Table $3-1$ ), and while ${ }^{13} \mathrm{C}$ levels were elevated in both the snail foot and trematode rediae, a pairwise comparison found no significant difference between these materials.

The one sample t-tests showed a significant effect of ${ }^{13} \mathrm{C}$ labelling for snail food as $\delta^{13} \mathrm{C}$ was higher when the labeled sodium carbonate was included $(\mathrm{t}=58.001, \mathrm{df}=5, \mathrm{P}<0.001)$. For the other lab materials, ${ }^{13} \mathrm{C}$ labelling did not have a significant for the $\delta^{13} \mathrm{C}$ in snail foot tissue $(\mathrm{t}$ $=2.287, \mathrm{df}=2, \mathrm{P}=0.150)$, but there was a marginally insignificant difference for the rediae tissue depending on whether the snail had received ${ }^{13} \mathrm{C}$ labelled food or not $(\mathrm{t}=3.707, \mathrm{df}=2, \mathrm{P}=$ 0.066), with a strong trend for a lower ratio of ${ }^{13} \mathrm{C}$ in the latter. The t-tests for mesocosm samples showed that the addition of ${ }^{13} \mathrm{C}$ labelled cercariae had a highly significant effect on the $\delta^{13} \mathrm{C}$ of oligochaete worms $(t=15.264, \mathrm{df}=8, \mathrm{P}<0.001)$ as these values were higher than samples from tanks that received unlabeled cercariae, or none at all. The addition of ${ }^{13} \mathrm{C}$ labelled cercariae had a marginally insignificant effect on the $\delta^{13} \mathrm{C}$ of diving beetles $(\mathrm{t}=1.800, \mathrm{df}=18, \mathrm{P}=0.089)$, with a trend for higher values, but no significant effect on those for dragonfly larvae $(t=-1.551, \mathrm{df}=$ $18, \mathrm{P}=0.138)$ and zooplankton $(\mathrm{t}=0.940, \mathrm{df}=9, \mathrm{P}=0.372)$. 


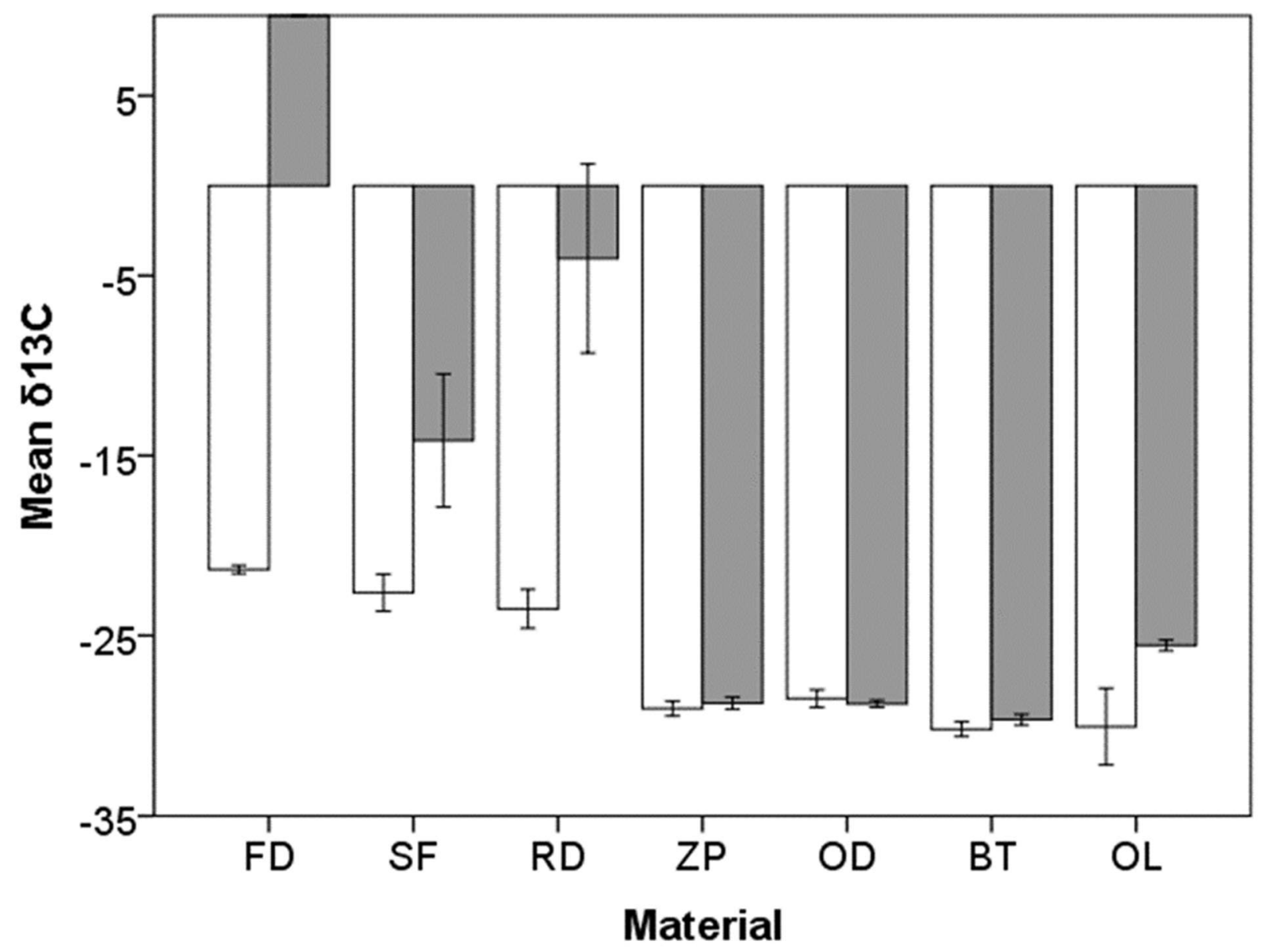

Error Bars: +/ $1 \mathrm{SE}$

Figure 3-1: Mean (+ S.E.) value of $\delta^{13} \mathrm{C}$ resulting from stable isotope analysis (SIA). As ${ }^{12} \mathrm{C}$ is naturally more abundant than ${ }^{13} \mathrm{C}$, less negative values indicate a higher ratio of the latter (i.e. higher $\delta^{13} \mathrm{C}$ ). White bars indicate samples that did not receive labeled ${ }^{13} \mathrm{C}$ while grey bars represent labelled samples. Both lab and mesocosm material are represented: $\mathrm{FD}=$ food, $\mathrm{SF}=$ snail foot, $\mathrm{RD}=$ rediae, $\mathrm{ZP}=$ zooplankton, $\mathrm{OD}=$ larval odonates, $\mathrm{BT}=$ diving beetles, and $\mathrm{OL}=$ oligochaete worms. Note that the $\delta^{13} \mathrm{C}$ value for ${ }^{13} \mathrm{C}$ labeled food was 421.78 but cut off here to allow appropriate scaling of the y-axis. 


\section{Discussion}

My results indicate that trematode cercariae were successfully labelled with ${ }^{13} \mathrm{C}$, and that carbon derived from these free-living parasite stages were detected within other taxa kept in experimental mesocosms to which cercariae were added. Although the snail head/foot samples did not show a significant difference in their ratio of ${ }^{13} \mathrm{C}$ to ${ }^{12} \mathrm{C}\left(\delta^{13} \mathrm{C}\right)$, the snail body material containing trematode rediae showed a strong trend for higher $\delta^{13} \mathrm{C}$, thus it is highly likely that the cercariae produced by these rediae also had higher $\delta^{13} \mathrm{C}$. Given that rediae consume tissue from the digestive-gonadal complex of their snail hosts (see Introduction), it appears that the feeding of labeled food to snails results in the accumulation of ${ }^{13} \mathrm{C}$ in select tissues which is then acquired by the parasites. Given that I only had three pooled samples for labelled and unlabelled snails, respectively, that represented 9 total snails per food treatment, it is quite likely that a significant effect of ${ }^{13} \mathrm{C}$ labeling would have been observed with a greater sample size because the snail food was clearly successfully labeled. However, the presence of elevated ${ }^{13} \mathrm{C}$ ratios varied among taxa in a manner that may reflect different consumption of cercariae biomass based on trophic level.

Within the mesocosms, the addition of ${ }^{13} \mathrm{C}$ labelled cercariae either did not generate a strong enough signal for certain taxa, or the cercariae were not consumed. The highest $\delta^{13} \mathrm{C}$ was seen in oligochaete worms, suggesting that cercariae biomass was consumed in great enough quantities to generate a strong signal for this taxon. With no potential second intermediate hosts

present to infect that I am aware of, and the lack of significant differences in ${ }^{13} \mathrm{C}$ ratios compared to the controls (unlabeled or no cercariae) for the other mesocosm taxa, it is likely that the majority of added cercariae died and contributed to the detrital biomass, leading to their consumption by the oligochaetes. This may indicate that the largest contribution of cercariae to 
nutrient and energy cycling and flow within freshwater habitats is mediated by decomposers and detrivores, and not by predators. Within ecosystems, the predation of cercariae is often discussed in the context of a reduction in transmission to hosts (Orlofske et al., 2012; Thieltges et al., 2013). As a diversity of predators means more mouths consuming cercariae, predators may inadvertently protect intermediate hosts from infection (Orlofske et al., 2012; Thieltges et al., 2013) However, as discussed earlier in this chapter, only a fraction of the cercariae produced will ever infect their intended hosts; the vast majority remain to either be eaten, or die and then be consumed. My results suggest that the latter fate may be common for cercariae.

Although dragonfly larvae from tanks with ${ }^{13} \mathrm{C}$ labeled cercariae added showed no significant spike in their $\delta^{13} \mathrm{C}$, they have been shown in past experiments to consume cercariae of various trematode species (Orlofske et al., 2015; Rohr et al., 2015; Catania et al., 2016). These include relatively small-bodied cercariae such as those used by Catania et al., (2016) that are similar in size to those of the family Plagiorchiidae used here. I performed a series of experiments to determine if this species of dragonfly larvae consume plagiorchiid cercariae, which suggested they do (data not shown). Considering the overall volume of each mesocosm relative to limited number of larval odonates in each (three), it is possible the weekly additions of cercariae were simply not large enough to allow for adequate consumption to allow for a strong ${ }^{13} \mathrm{C}$ signal. Possible lack of spatial overlap between the larval odonates and added cercariae may also have played a role. Dragonfly larvae exhibit several hunting strategies, including sitting and waiting for prey that are visually detected, or engage in active pelagic foraging, dependent on the presence of predators that might target them (Johansson, 1993). Smaller larval dragonflies tend to use the cover of the benthic zone to avoid predation (Johansson, 1993). If the dragonfly larvae were not particularly active, and/or tended to rest on the bottom of the tanks, the potential for 
cercariae to enter their feeding range may have been low. In addition, the size of dragonfly larvae and their prey can impact their choice of prey (Catania et al., 2016), and may have resulted in some larvae targeting zooplankton such as Daphnia over the cercariae. The continuous availability of zooplankton upon which to feed could also have caused predator satiation such that they consumed few cercariae given that these were in relatively low abundance and only present in the water column for less than 24 hours considering their short lifespan.

Diving beetles from tanks with ${ }^{13} \mathrm{C}$ labeled cercariae showed a strong trend for higher $\delta^{13} \mathrm{C}$, and it is likely that this difference would have been significant with a greater number of samples. The results therefore suggest that some predation on cercariae by diving beetles occurred, and this was supported by targeted feeding trials performed in the lab (data not shown). Diving beetles are strong swimmers and pelagic hunters (Cobbaert et al., 2010), probably encountering cercariae in the water column more often than larval dragonflies. My results thus comprise the first report of cercariae consumption by this taxon to the best of my knowledge. The zooplankton samples showed no effect of adding ${ }^{13} \mathrm{C}$ labeled cercariae, and this could reflect a true lack of movement for cercariae-derived carbon or my methodology. I had hypothesized that zooplankton may directly consume cercariae, or perhaps algae containing ${ }^{13} \mathrm{C}$ after breakdown of dead cercariae by decomposers. Due to the logistical hurdle of gathering enough zooplankton from each mesocosm to provide sufficient biomass for SIA, these samples were not homogenous (even though they were dominated by Daphnia). Because the entire pooled community was analyzed, may have led to a lack of ${ }^{13} \mathrm{C}$ label if the different zooplankton taxa differed greatly in their consumption of cercariae biomass through various pathways. If each zooplankton taxon present were to be tested separately with enough mass for each in future studies, this will clarify whether there are differing ratios of carbon isotopes. 
Oligochaete worms live in the benthic sediment where they consume detrital matter and deposit it as feces (Leppänen and Kukkonen, 1998). Since they consume the sediment, they do not select for what matter they ingest, meaning any matter present will be digested (Leppänen and Kukkonen, 1998). This creates a high likelihood that detrital cercarial biomass will be consumed, and egested, in the benthic sediment because benthic invertebrates tend to take on a similar carbon isotope ratio to that found in the phytoplankton that comprises most of their food (James et al., 2000). Given the elevated ${ }^{13} \mathrm{C}$ ratios found in my oligochaete samples, this suggests that cercarial matter can be efficiently consumed and incorporated by these worms. The oligochaetes may then be consumed by predators, such as larval insects or juvenile fish, leading to the indirect movement of cercariae-derived carbon to secondary consumers (Loden, 1974; Weber and Traunspurger, 2015).

As my results show that the use of carbon isotopes for the labelling of cercariae is effective in detecting consumption of their biomass in some freshwater taxa, future studies should focus on specific groups, particularly decomposers and detrivores, to provide in-depth food webs that better represent the contribution of free-living parasite stages to nutrient cycling and energy flow. While only utilized in a model system here within self-contained experimental mesocosms, this approach could also potentially be applied to natural ecosystems to determine the scope and extent of cercariae influences on their environment. To do so, future studies employing mesocosms should increase the number of cercariae added each week and assess resulting signal strength, as well as conduct complementary experiments to determine the threshold for the effective labelling of cercariae and their snail hosts. Studies may also be conducted longer to allow for the breakdown of cercarial biomass to potentially join and label algae within the mesocosm, providing an alternative pathway for cercarial carbon to end up in 
zooplankton and their predators. Such work will allow us to better understand the possible roles of parasites in aquatic ecosystems. 


\section{Chapter 4: General Discussion}

The overall goal of my thesis was to expand our current understanding of how parasites, particularly free-living infectious stages, may impact aquatic food webs as prey rather than by virtue of infecting hosts. Often when parasites are added into food web structures, it is from the

perspective of their effects on hosts. Parasites can affect host mortality, reproductive success, and behaviour (McCallum and Dobson, 1995; Lafferty and Morris, 1996), but this host-centric focus has historically left parasites out of food webs. The inclusion of parasites, especially those with complex, multi-host life cycles, can dynamically alter food webs by adding to their complexity (Lafferty et al., 2008). However, free-living parasite phases, such as trematode cercariae, are not included in most cases, and even if they are, the implications are largely focused on those related to transmission. This is problematic because these free-living phases represent massive amounts of biomass that for the most part never reach their intended fate - infecting the next host in the life cycle (Preston et al., 2013). This biomass does not just disappear; instead, much of it could be consumed by predators, or detritivores after the death of these typically short-lived infectious stages. While many previous studies have focused on consumption of infectious stages in the context of reduction of transmission to secondary hosts (Orlofske et al., 2012), the inclusion of trematode cercariae as prey in food webs in their own right represents a gap in our current thinking that needs to be filled. Consequently, the primary objective of my thesis was to examine how cercariae interact with other select taxa of freshwater ecosystems such as ponds by serving as a source of food. To do so, I focused on how the presence of cercariae as alternate prey may affect predation upon zooplankton, and also sought to identify consumers of cercariae-derived carbon within experimental mesocosms containing a model freshwater community. 
In Chapter 2 of this thesis, I sought to determine how the presence of free-living cercariae might impact the population abundance of a common freshwater zooplanktonic taxon (Daphnia sp.) in the absence or presence of larval dragonflies known to consume both (Catania et al., 2016). I hypothesized that cercariae would have a positive effect on Daphnia population abundance, primarily by acting as alternative prey for dragonfly larvae. I conducted this experiment within small outdoor mesocosms that contained Daphnia sp., dragonfly larvae (Leucorrhinia intacta), and lymnaeid snails (Stagnicola elodes) that were uninfected or infected with trematodes in the family Plagiorchiidae. The production of cercariae from the infected snails provided a constant influx to simulate what may occur in natural settings to generate cooccurrence with Daphnia, thus providing alternative prey for the larval dragonflies. Weekly nondestructive sampling allowed me to track the abundance of Daphnia over the 5-week experiment.

My results supported my initial hypothesis by showing that there was a significant positive influence of infected snails (and therefore cercariae) on Daphnia abundance when predators were present. In contrast, the presence of predators was associated with lower Daphnia numbers when only uninfected snails were present. When predators were absent but infected snails present, I found a marginally insignificant positive effect on the population abundance of Daphnia, suggesting that cercariae might have a beneficial impact through other means than serving as alternative prey. As described in Chapter 1, many zooplanktonic organisms may actually consume cercariae, giving rise to the possibility that cercariae could be an important food item for taxa not considered as predators. Considering that global climate change is predicted to cause a temperature-mediated increase in the number of cercariae produced within host snails (Poulin, 2006), and that warm water temperatures also promote eutrophication that increases cercarial production (Johnson et al., 2007), a greater abundance and longer seasonal 
presence of cercariae may perhaps benefit zooplankton communities. Equally important would be the potential loss of infected snails for various reasons, such as poor heat tolerance (Paull and Johnson, 2011), and the subsequent reduction of cercariae production that could prove detrimental to aquatic food webs.

In order to determine if Daphnia do readily consume cercariae, future experiments examining homogenous Daphnia populations with and without cercariae present could shed light on any positive interactions outside of predation by also tracking population abundance. The great variety of predators that are either assumed or known to consume cercariae (See Table 1.1) may also have differing influences on Daphnia population abundance, and thus the testing of several combinations would be beneficial. In a similar fashion, using a diverse range of trematode species in future experiments would be informative due to the morphological and behavioural differences in their cercariae (see Chapter 1), thus helping us to understand their broad ability to serve as alternate prey and reduce predation upon zooplankton.

In Chapter 3, my objectives were two-fold. First, I sought to determine if cercariae could be successfully labelled with the stable carbon isotope ${ }^{13} \mathrm{C}$, and whether this would allow me to trace consumption of their biomass through a model freshwater food web. Second, I attempted to increase our understanding of the pathways through which cercariae-derived carbon might move within freshwater food webs by identifying possible consumers through altered ratios of ${ }^{13} \mathrm{C}$ to ${ }^{12} \mathrm{C}\left(\delta^{13} \mathrm{C}\right)$. Labelling organisms using ${ }^{13} \mathrm{C}$ to trace carbon flow has been successfully demonstrated in a myriad of taxa, including plants, plankton and fish (Svejcar et al., 1989; Rosenfeld and Roff, 1992; Herman et al., 2000); however, no studies to date have utilized this approach with trematode cercariae that I am aware of. To achieve this stable isotope labelling, I made food with which to feed infected snails that included sodium carbonate with ${ }^{13} \mathrm{C}$ substituted 
for ${ }^{12} \mathrm{C}$ in an attempt to introduce a large amount of ${ }^{13} \mathrm{C}$ into the body of the snails. In Chapter 1 , I discuss the general life cycle of trematodes, including the phase within snails that produces cercariae through asexual reproduction; it is during this phase that snail tissue is consumed by trematode rediae, ultimately producing cercariae. Carbon derived from the snail should then be transferred into the cercariae, which provided an excellent potential pathway by which to label cercariae with ${ }^{13} \mathrm{C}$.

For this experiment, I constructed simple model freshwater food webs within experimental mesocosms with common taxa that represented key trophic levels: larval dragonflies and diving beetles (predators, and therefore secondary consumers), oligochaete worms (benthic detrivores, and therefore decomposers), and a zooplankton community dominated by Daphnia (primary consumers). I ran this experiment for four weeks, and each week I collected cercariae from infected snails fed either ${ }^{13} \mathrm{C}$ labelled food or unlabeled food and introduced them into the mesocosms, with some mesocosms instead receiving a sham addition of water. This was followed by stable isotope analysis of the food, snails (head/foot region and body portion containing rediae), and the mesocosm inhabitants. Given that the labelled snail food and the body of the snail both proved to contain higher ratios of ${ }^{13} \mathrm{C}$ (See Table 3-1 in Chapter 3) when compared to unlabelled counterparts, I determined that the labelling of cercariae with ${ }^{13} \mathrm{C}$ was successful and this technique can be refined and extended in future studies having now established the proof of concept.

With respect to detecting elevated $\delta^{13} \mathrm{C}$ within organisms from mesocosms that received ${ }^{13} \mathrm{C}$ labeled cercariae, I only found a noticeable spike in the oligochaete worms. This is contrary to the literature to date, which suggests that cercariae are consumed by zooplankton (Christensen, 2009), as well as ample evidence for their consumption by dragonfly larvae 
(Orlofske et al., 2015; Rohr et al., 2015; Catania et al., 2016). However, my Chapter 2 results support the high consumption of cercariae of the family Plagiorchiidae by the same larval odonates (Leucorrhinia intacta) given that their presence promoted the high abundance of Daphnia when both prey were present, as did experimental feeding trials with these predators and cercariae that are not included in this thesis. In contrast, there was a strong trend for elevated $\delta^{13} \mathrm{C}$ within diving beetles, suggesting that they consumed some cercariae, as assumed by Rohr et al., (2015) but not previously demonstrated.

This being said, there are various possible reasons why I did not detect elevated $\delta^{13} \mathrm{C}$ within larval odonates in this experiment. For instance, it is likely that the cercariae additions $(\overline{\mathrm{x}}$ $=90$ per week) were simply too small to generate a large enough difference in ${ }^{13} \mathrm{C}$ levels if the mesocosms were too sparsely populated with larval odonates for their volume (three dragonfly larvae/ 250 L). Another possible limitation was the continuous presence of zooplankton, which are common prey for dragonfly larvae and diving beetles (Klecka and Boukal, 2012). This meant that their predation on cercariae may have been dampened as one weekly addition may have been ignored by satiated predators. It could also have meant that the limited numbers of cercariae reduced potential encounter rates with dragonfly larvae. Given the benthic nature of hunting behaviour exhibited larval dragonflies as they sit and wait to ambush prey (Burks et al., 2001), and the relatively small number of cercariae added, it is possible that not enough spatial and temporal overlap occurred before the death of cercariae.

With cercariae dying on average 24 hours after being emerging from snails (Koprivnikar et al., 2006) and the large amount of overall biomass produced (Preston et al., 2013), that there was a large labelling effect in the oligochaete worms is logical. The resulting influx of cercarial carbon into the benthic zone could potentially prove an important pathway for carbon cycling in 
aquatic ecosystems. In this sense, the predation of cercariae may take a back seat to consumption of their biomass by detritivores in terms of overall importance to aquatic food webs. If this proves to be an important fate of cercarial biomass through future studies that expand upon my experiment, a greater production of cercariae due to the factors mentioned above (e.g., climate change) could mean more organic matter present within the benthic zone for breakdown and release of carbon to primary producers.

A limitation for the experiments in Chapters 2 and 3 was the unintended colonization of my mesocosms by mosquito and midge larvae, among others. Although both of my field experiments had some form of barrier to exclude foreign organisms from entering (window screen mesh in both cases), it proved inadequate from blocking everything under all circumstances. For example, heavy rains caused the screening to become distorted and temporarily cause gaps before I was able to fix these. To account for this in Chapter 3, the entire zooplankton community of each mesocosm was sampled and sent for stable isotope analysis rather than just Daphnia in the event that other planktonic fauna also consumed cercariaederived carbon considering that copepods, ostracods and amphipods have been reported as cercariae predators (see Chapter 1). In Chapter 2, it was assumed than any random effects related to unintended colonization would be evenly dispersed across all replicates and treatments (12 per treatment with four treatments total $=48$ ), especially because treatments were randomly assigned to plastic bins.

Another limitation common to both experiments was the possible impact of larval dragonfly size on their predation of Daphnia. Since dragonfly larvae exhibit preferential predation based on the size of the prey available and that of their own jaws, smaller dragonflies (with a head width between 1 and $3.5 \mathrm{~mm}$ ) tend to consume more cercariae than Daphnia if the 
latter are relatively larger (Catania et al., 2016). I attempted to account for this by selecting dragonfly larvae that were roughly equivalent in body length for use in my experiments $(\bar{x}=5.1$ $\mathrm{mm}$, S.D. $=0.5 \mathrm{~mm}$ ). Larger dragonfly larvae have been shown to consume cercariae at a reduced rate compared to Daphnia (Catania et al., 2016), suggesting that future experiments using smaller larvae may find a stronger effect for the questions in both of my experiments.

By showing that free-living parasite infectious stages, specifically the cercariae of trematodes, affect zooplankton via altered predator-prey dynamics, as well as their significant consumption by freshwater taxa outside of predators, it is my hope that my findings will further our understanding of how parasites fit into food webs by serving as prey or a source of nutrients and energy. In addition, my demonstration of ${ }^{13} \mathrm{C}$ as a tracer for cercariae-derived carbon represents the first time that this has been experimentally proven as effective, and creates new potential ways to determine how cercariae interact within food webs by use of stable carbon isotope analysis that are currently absent in the literature. While previous studies have shown consumption of cercariae by dragonfly larvae, my results are the first to show how this predation may beneficially impact the abundance of common zooplankton such as Daphnia. Daphnia are primary consumers of phytoplankton (Zollner et al., 2003), and important stores of fatty acids for higher trophic levels (Brett et al., 2006), thus preserving healthy populations of such zooplankton likely promotes productive and stable ecosystems. Given the state of flux in aquatic ecosystems due to global climate change and other perturbations (Parmesan and Yohe, 2003), it is important to shed light on understudied areas such as the importance of parasites as prey within food webs to understand how food web complexity and resilience may be influenced if both free-living and parasitic members are affected. 


\section{Literature Cited}

Akre, B.G. and Johnson, D.M. (1979) Switching and sigmoid functional response curves by damselfly naiads with alternative prey available. J. Animal Ecol. 48(3): 703-720.

Anderson, T., and Hessen, D.O. (1991) Carbon, nitrogen, and phosphorus content of freshwater zooplankton. Limnol. Oceanogr. 36(4): 807-814.

Anucherngchai, S., Tejangkura, T., and Chontananarth, T. (2016) Epidemiological situation and molecular identification of cercarial stage in freshwater snails in Chao-Phraya Basin, Central Thailand. Asian. Pac. J. Trop. Biomed. 6(6): 539-545.

Brett, M.T. and Goldman, C.R. (1997) Consumer versus resource control in freshwater pelagic food webs. Science. 275(5298): 384-386.

Brett, M.T., Muller-Navarra, D.C., Ballantyne, A.P., Ravet, J.L., and Goldman, C.R. (2006) Daphnia fatty acid composition reflects that of their diet. Limnol. Oceanogr. 51(5): 24282437.

Burks, R.L., Jeppesen, E., and Lodge, D.M. (2001) Pelagic prey and benthic predators: impact of odonate predation on Daphnia. J. N. Am. Benthol. Soc. 20(4): 615-628.

Cabana, G., and Rasmussen, J.B. (1994) Modelling food chain structure and contaminant bioaccumulation using stable nitrogen isotopes. Nature. 372(6503): 255-257.

Calbet, A., and Landry, M.R. (2004) Phytoplankton growth, microzooplankton grazing, and carbon cycling in marine systems. Limnol. Oceanogr. 49(1): 51-57.

Carpenter, S.R., Kitchell, J.F. and Hodgson, J.R. (1985) Cascading trophic interactions and lake productivity. BioScience. 35(10): 634-639.

Catania, S.V.L., Koprivnikar, J., and McCauley, S.J. (2016) Size-dependent predation alters interactions between parasites and predators. Can. J. Zool. 94(9): 631-635. 
Christensen, N.O. (2009) Schistosoma mansoni: interference with cercarial host-finding by various aquatic organisms. J. Helminthol. 53(1): 7-14.

Cobbaert, D., Bayley, S.E., and Greter, J.L. (2010) Effects of a top invertebrate predator (Dytiscus alaskanus; Coleoptera: Dytiscidae) on fishless pond ecosystems. Hydrobiologia. 644: 103 - 114.

Combes, C. (1996) Parasites, biodiversity and ecosystem stability. Biodiversity Conserv. 5(8): 953-962.

Cort, W.W. (1914) Larval trematodes from north american fresh-water snails. J. Parasitol. I(2): $65-84$.

Cribb, T.H., Bray, R.A., Olson, P.D., and Littlewood, D.T.J. (2003) Life cycle evolution in the digenea: A new perspective from phylogeny. Adv. Parasitol. 54: 197-254.

Culver, D.A., Boucherle, M.M., Bean, D.J. and Fletcher, J.W. (1985) Biomass of freshwater crustacean zooplankton from length-weight regressions. Can. J. Fish. Aquat. Sci. 42(8): $1380-1390$.

Dobson, A., Lafferty, K.D., Kuris, A.M., Hechinger, R.F. and Jetz, W. (2008) Homage to linnaeus: How many parasites? How many hosts? PNAS. 105(Supplement 1): 1148211489.

Dol, H., Yurlova, N.I., Vodyanitskaya, S.N., Kanaya, G., Shikano, S., and Kikuchi, E. (2010) Estimating isotope fractionation between cercariae and host snail with the use of isotope measurement designed for very small organisms. J. Parasitol. 96(2): 314-317.

Dzialowski, A.R., Lennon, J.T., and Smith, V.H. (2007) Food web structure provides biotic resistance against plankton invasion attempts. Biol. Invasions. 9: 257-267. 
Ebert, D. (1994) Virulence and local adaptation of a horizontally transmitted parasite. Science. 265: 1084-1086.

Esch, G.W., Barger, M.A., and Fellis, K.J. (2002) The transmission of digenetic trematodes: Style, elegance, complexity. Integ. and Comp. Biol. 42: 304-312.

Faltýnková, A. (2005) Larval trematodes (Digenea) in molluscs from small water bodies near Šeské Budšjovice, Czech Republic. Acta Parasitol. 50(1): 49-55.

Finlay, J.C. (2001) Stable-carbon-isotope ratios of river biota: implications for energy flow in lotic food webs. Ecology. 82(4): $1052-1064$.

Gliwicz, Z.M. and Pijanowska, J. (1989) The role of predation in zooplankton succession. In Plankton ecology (pp. 253-296). Springer, Berlin, Heidelberg.

Goater, T.M., Goater, C.P., and Esch, G.W. (2014) Parasitism: the diversity and ecology of animal parasites ( $2^{\text {nd }}$ ed.). Cambridge University Press.

Graeve, M., Albers, C., and Kattner, G. (2005) Assimilation and biosynthesis of lipids in Arctic Calanus species based on feeding experiments with a 13C labelled diatom. J. Exp. Mar. Bio. Ecol. 317(1): 109-125.

Grey, J. (2006) The use of stable isotope analyses in freshwater ecology: Current awareness. Pol. J. Ecol. 54(4): 563-584.

Gu, B., Schell, D.M., and Alexander, V. (1994) Stable carbon and nitrogen isotopic analysis of the plankton food web in a subarctic lake. Can. J. Fish. Aquat. Sci. 51: 1338 - 1344.

Haas, W. (1994) Physiological analyses of host-finding behavior in trematode cercariae adaptations for transmission success. Parasitology. 109: S15-S29.

Hanson, J.M. and Peters, R.H. (1984) Empirical prediction of crustacean zooplankton biomass and profundal macrobenthos biomass in lakes. Can. J. Fish. Aquat. Sci. 41(3) :439-445. 
Hansen, P.J., and Bjørnsen, P.K. (1997) Zooplankton grazing and growth: Scaling within the 2-

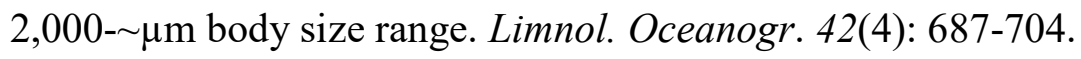

Hatcher, M.J., Dick, J.T., and Dunn, A.M. (2006). How parasites affect interactions between competitors and predators. Ecol. Lett. 9(11): 1253-1271.

Hays, G.C. (2002) A review of the adaptive significance and ecosystem consequences of zooplankton diel vertical migrations. Hydrobiologia. 503(1): 163-170.

Hechinger, R.F., and Lafferty, K.D. (2005) Host diversity begets parasite diversity: bird final hosts and trematodes in snail intermediate hosts. Proc. R. Soc. Lond. B: Biol. Sci. 272(1567): 1059-1066.

Herman, P.M.J., Middelburg, J.J., Widdows, J., Lucas, C.H., and Heip, C.H.R. (2000) Stable isotopes as trophic tracers: combining field sampling and manipulative labelling of food resources for macrobenthos. Mar. Ecol. 204: 79-92.

Hopkins, S.R., Wyderko, J.A., Sheehy, R.R., Belden, L.K., and Wojdak, J.M. (2013) Parasite predators exhibit a rapid numerical response to increased parasite abundance and reduce transmission to hosts. Ecol. Evolut. 3(13): 4427-4438.

Hudson, P.J., Dobson, A.P., and Lafferty, K.D. (2006) Is a healthy ecosystem one that is rich in parasites? Trends. Ecol. Evolut. 21(7): 381-385.

Hülsmann, S. and Weiler, W. (2000) Adult, not juvenile mortality as a major reason for the midsummer decline of a Daphnia population. J. Plankton. Res. 22(1): 151-168.

Hunt, R.J. and Swift, M. (2010) Predation by larval damselflies on cladocerans. J. Freshw. Ecol. 25(3):345-351.

James, M.R., Hawes, I., Weatherhead, M., Stanger, C., and Gibbs, M. (2000) Carbon flow in the littoral food web of an oligotrophic lake. Hydrobiologia. 441: 93-106. 
Jeffries, M. (1988) Individual vulnerability to predation: the effect of alternative prey types. Freshwater Biol. 19(1): 49-56.

Johansson, F. (1993) Intraguild predation and cannibalism in odonate larvae - effects of foraging behaviour and zooplankton availability. Oikos. 66(1): 80-87.

Johnson, P.T., Chase, J.M., Dosch, K.L., Hartson, R.B., Gross, J.A., Larson, D.J., Sutherland, D.R. and Carpenter, S.R. (2007) Aquatic eutrophication promotes pathogenic infection in amphibians. PNAS. 104(40): 15781-15786.

Johnson, P.T., and Hartson, R.B. (2009). All hosts are not equal: explaining differential patterns of malformations in an amphibian community. J. Animal Ecol. 78: 191-201.

Johnson, P.T.J., Dobson, A., Lafferty, K.D., Marcogliese, D.J., Memmott, J., Orlofske, S.A., Poulin, R., and Thieltges, D.W. (2010) When parasites become prey: ecological and epidemiological significance of eating parasites. Trends. Ecol. Evolut. 25(6): 362-371.

Johnson, P.T., Wood, C.L., Joseph, M.B., Preston, D.L., Haas, S.E., and Springer, Y.P. (2016) Habitat heterogeneity drives the host-diversity-begets-parasite-diversity relationship: evidence from experimental and field studies. Ecol. Lett. 19(7): 752-761.

Kainz, M., Arts, M.T. and Mazumder, A. (2004) Essential fatty acids in the planktonic food web and their ecological role for higher trophic levels. Limnol. Oceanog. 49(5): 1784-1793.

Kendall, C., and Caldwell, E.A. (1998). 'Fundamentals of Isotope Geochemistry' in Isotope Tracers in Catchment Hydrology. Elsevier Science, Amsterdam. 51-86.

Klecka, J., and Boukal, D.S. (2012) Who eats whom in a pool? a comparative study of prey selectivity by predatory aquatic insects. PLOS One. 7(6): e37741. 
Knight, W. B., Lawrence, S., Ritchie, F. L., and Chiriboga, J. (1970). Cercariophagic activity of guppy fish (Lebistes reticulates) detected by cercariae labeled with radioselenium (75sE). Amer. J. Trop. Med. Hyg. 19: 620-625.

Koprivnikar, J., Forbes, M.R., and Baker, R.L. (2006) Effects of atrazine on cercarial longevity, activity and infectivity. J. Parasitol. 92(2): 306-311.

Koprivnikar, J., Riepe, T.B., Calhoun, D.M. and Johnson, P.T. (2018) Whether larval amphibians school does not affect the parasite aggregation rule: testing the effects of host spatial heterogeneity in field and experimental studies. Oikos. 127(1): 99-110.

Kuris, A.M., Hechinger, R.F., Shaw, J.C., Whitney, K.L., Aguirre-Macedo, L., Boch, C.A., Dobson, A.P., Dunham, E.J., Fredensborg, B.L., Huspeni, T.C., Lorda, J., Mababa, L., Mancini, F.T., Mora, A.B., Pickering, M., Talhouk, N.L., Torchin, M.E., and Lafferty, K.D. (2008) Ecosystem energetic implications of parasite and free-living biomass in three estuaries. Nature. 454: 515-518.

Lafferty, K.D. and Morris, A.K. (1996) Altered behavior of parasitized killifish increases susceptibility to predation by bird final hosts. Ecology. 77(5): 1390-1397.

Lafferty, K.D., Allesina, S., Arim, M., Briggs, C.J., De Leo, G., Dobson, P., Dunne, J.A., Johnson, P.T.J., Kuris, A.M., Marcogliese, D.J., Martinez, N.D., Memmott, J., Marquet, P.A., McLaughlin, J.P., Mordecai, E.A., Pascual, M., Poulin, R., and Thieltges, D.W. (2008) Parasites in food webs: the ultimate missing links. Ecol. Lett. 11: 533-546.

Leppänen, M.T., and Kukkonen, J.V.K. (1998) Factors affecting feeding rate, reproduction and growth of an oligochaete Lumbriculus variegatus (Müller). Hydrobiologia. 377: 183-194. 
Lo, C.T., and Lee, K.M. (1996) Pattern of emergence and the effects of temperature and light on the emergence and survival of heterophyid cercariae (Centrocestus formosanus and Haplorchis pumilio). J. Parasitol. 82(2): 347-350.

Loden, S.M. (1974) Predation by chironomid (diptera) larvae on oligochaetes. Limnol. Oceanog. 19(1): 156-159.

Loy, C., and Haas, W. (2001) Prevalence of cercariae from Lymnaea stagnalis snails in a pond system in southern germany. J. Parasitol. Res. 87(10):878-882.

Lynch, M. (1979) Predation, competition, and zooplankton community structure: an experimental study. Limnol. Oceanog. 24(2): 253-272.

Maloney, C.L., and Field, J.G. (1991) The size-based dynamics of plankton food webs. I. A simulation model of carbon and nitrogen flows. J. Plankton. Res. 13(5): 1003-1038.

Marcogliese, D.J. (2005) Parasites of the superorganism: Are they indicators of ecosystem health? Int. J. Parasitol. 35(7): 705-716.

Marcogliese, D.J., and Cone, D.K. (1997) Food webs: a plea for parasites. TREE. 12(8): 320325.

Marsit, C.J., Fried, B., Sherma, J. (2000) Neutral lipids in cercariae, encysted metacercariae, and rediae of Echinostoma caproni. J. Helminthol. 74(4): 365-367.

McCallum, H., and Dobson, A. (1995) Detecting disease and parasite threats to endangered species and ecosystems. Trends. Ecol. Evolut. 10:190-194.

Møller, A.P. (1998) Evidence of larger impact of parasites on hosts in the tropics: investment in immune function within and outside the tropics. Oikos. 82(2): 265-270.

Moraels, E. (2008) Ribeiroia ondatrae flatworm life cycle. http://www.scienceart.com/image $/$ id $=3561 \&$ search $=1$. 
Morley, N.J. (2012) Cercariae (Platyhelminthes: Trematoda) as neglected components of zooplankton communities in freshwater habitats. Hydrobiologia. 691: 7-19.

Mouritsen, K.N., and Poulin, R. (2002) Parasitism, community structure and biodiversity in intertidal ecosystems. Parasitology. 124: S101-S117.

Orlofske, S.A., Jadin, R.C., Preston, D.L. and Johnson, P.T. (2012) Parasite transmission in complex communities: predators and alternative hosts alter pathogenic infections in amphibians. Ecology. 93(6): 1247-1253.

Orlofske, S. A, Jadin, R.C., and Johnson, P.T.J. (2015) It's a predator-eat-parasite world: How characteristics of predator, parasite and environment affect consumption. Oecologia. 178(2): 537-547.

Pace, M.L. and Orcutt, J.D. (1981) The relative importance of protozoans, rotifers, and crustaceans in a freshwater zooplankton community. Limnol.Oceanog. 26(5): 822-830.

Parmesan, C., and Yohe, G. (2003) A globally coherent fingerprint of climate change impacts across natural systems. Nature. 421(6918): 37-42.

Pascual, M., and Dunne, J.A. (2006) Ecological networks: Linking structure to dynamics in food webs. Oxford University Press.

Paull, S.H., and Johnson, P.T. (2011) High temperature enhances host pathology in a snailtrematode system: possible consequences of climate change for the emergence of disease. Freshwater Biol. 56(4): 767-778.

Pietrock, M. and Marcogliese, D.J. (2003) Free-living endohelminth stages: at the mercy of environmental conditions. Trends. Parasitol. 19(7): 293-299.

Post, D.M. (2002) Using stable isotopes to estimate trophic position: models, methods and assumptions. Ecology. 83(3): 703-718. 
Poulin, R. (2006) Global warming and temperature-mediated increases in cercarial emergence in trematode parasites. Parasitology. 132(1): 143-151.

Preston, D.L., Orlofske, S.A., Lambden, J.P., and Johnson, P.T.J. (2013) Biomass and productivity of trematode parasites in pond ecosystems. J. Anim. Ecol. 82(3): 509-517.

Rigler, F.H. (1975) The concept of energy flow and nutrient flow between trophic levels. Unifying concepts in ecology. The Hague and Centre for Agricultural Publishing. p 1426.

Rohde, K. (1982) Ecology of Marine Parasites. University of Queensland Press, St Lucia, QLD, Australia.

Rohr, J.R., Civitello, D.J., Crumrine, P.W., Halstead, N.T., Miller, A.D., Schottheofer, A.M., Stenoien, C., Johnson, L.B., and Beasley, V.R. (2015) Predator diversity, intraguild predation, and indirect effects drive parasite transmission. PNAS. 112(10): 3008 - 3013 .

Rosenfeld, J. S., and Roff, J.C. (1992) Examination of the carbon base in southern ontario streams using stable isotopes. Freshw. Sci. 11(1): 1-10.

Rounick, J.S., and Winterbourn, M.J. (1986) Stable carbon isotopes and carbon flow in ecosystems. Bioscience. 36(7): 171-177.

Rowan, W. B. (1958). Daily periodicity of Schistosoma mansoni cercariae in PuertoRican waters. Amer. J. Trop. Med. Hyg. 7(4): 374-381.

Schell, S.C. (1985) Handbook of trematodes of North America north of Mexico. University of Idaho Press, Moscow.

Schindler, D.E., Kitchell, J.F., He, X., Carpenter, S.R., Hodgson, J.R. and Cottingham, K.L. (1993) Food web structure and phosphorus cycling in lakes. Trans. Am. Fish. Soc. 122(5): 756-772. 
Schotthoeffer, A.M., Labak, K.M., and Beasley, V.R. (2007) Ribeiroia ondatrae cercariae are consumed by aquatic invertebrate predators. J. Parasitol. 93(5): 1240-1243.

Schriver, P., Bøgestrond, J., Jeppeson, E., and Søndergaard, M. (1995) Impact of submerged macrophytes on fish-zooplankton-phytoplankton interactions: large-scale enclosure experiments in a shallow eutrophic lake. Freshwater. Biol. 33: 255-270.

Schwartz, S.S., and Cameron, G.N. (1993) How do parasites cost their hosts? Preliminary answers from trematodes and Daphnia obtuse. Limnol. Oceanogr. 38(3): 602-612.

Semlitsch, R.D., Boone, M.D. and Dodd Jr, C.K. (2010) Aquatic mesocosms. Amphibian ecology and conservation: a handbook of techniques [Techniques in Ecology \& Conservation Series]. 87-104.

Seppälä, O., Karvonen, A., and Valtonen, E.T. (2004) Parasite-induced change in host behaviour and susceptibility to predation in an eye fluke-fish interaction. Animal Behav. 68(2): 257263.

Soldánová, M., Selbach, C. and Sures, B. (2016) The early worm catches the bird? Productivity and patterns of Trichobilharzia szidati cercarial emission from Lymnaea stagnalis. PloS one. 11(2): $\mathrm{e} 0149678$

Sorci, G., and Clobert, J. (1995) Effects of maternal parasite load on offspring life-history traits in the common lizard (Lacerta uivipara). J. Evol. Biol. 8(6): 711-713.

Svejcar, T.J., Boutton, T.W., and Trent, J.D. (1989) Assessment of carbon allocation with stable carbon isotope labeling. Agron. J. 82(1): 18-21.

Szuroczki, D. and Richardson, J.M. (2009) The role of trematode parasites in larval anuran communities: an aquatic ecologist's guide to the major players. Oecologia. 161(2): 371385. 
Taipale, S.J., Kainz, M.J., and Brett, M.T. (2011) Diet-switching experiments show rapid accumulation and preferential retention of highly unsaturated fatty acids in Daphnia. Oikos. 120(11): 1674-1682.

Thieltges, D.W., de Montaudouin, X., Fredensborg, B., Jensen, K.T., Koprivnikar, J., and Poulin, R. (2008) Production of marine trematode cercariae: a potentially overlooked path of energy flow in benthic systems. Mar. Ecol. Prog. Ser. 372: 147-155.

Thieltges, D.W., Amundsen, P.A., Hechinger, R.F., Johnson, P.T., Lafferty, K.D., Mouritsen, K.N., Preston, D.L., Reise, K., Zander, C.D., and Poulin, R. (2013) Parasites as prey in aquatic food webs: implications for predator infection and parasite transmission. Oikos. 122(10): 1473-1482.

Thomas, F., Crivelli, A., Cezilly, F., Renaud, F., De Meeus, T. (1997) Parasitism and ecology of wetlands: A review. Estuaries. 20(3): 646-654.

Vander Zanden, J.M., Casselman, J.M., and Rasmussen, J.B. (1999) Stable isotope evidence for the food web consequences of species invasions in lakes. Nature. 401: 464-467.

Vander Zanden, M., and Rasmussen, J.B. (1999) Primary consumer $\delta 13 \mathrm{C}$ and $\delta 15 \mathrm{~N}$ and the trophic position of aquatic consumers. Ecology. 80(4): 1395-1404.

Weber, S., and Traunspurger, W. (2015) The effects of predation by juvenile fish on the meiobenthic community structure in a natural pond. Freshwater Biol. 60(4): 2392-2409.

Wissinger, S.A. (1988a) Spatial distribution, life history and estimates of survivorship in a fourteen-species assemblage of larval dragon-flies (Odonata: Anisoptera). Freshwater Biol. 20(3): 29-340.

Wissinger, S.A. (1988b) Life history and size structure of larval dragonfly populations. J. North Am. Benthological Soc. 7(1): 13-28. 
Wojdak, J.M., Edman, R.M., Wyderko, J.A., Zemmer, S.A., Belden, L.K. (2014) Host density and competency determine the effects of host diversity on trematode parasite infection. PLOS one. 9.

Wu, L. and Culver, D.A. (1994) Daphnia population dynamics in western Lake Erie: regulation by food limitation and yellow perch predation. J. Great Lakes Res. 20(3): 537-545.

Yoder, H.R. and Coggins, J.R. (1998) Larval trematode assemblages in the snail Lymnaea stagnalis from southeastern Wisconsin. J. Parasitol. 84: 259-268.

Zöllner, E., Santer, B., Boersma, M., Hoppe, H.G., and Jürgens, K. (2003) Cascading predation effects of daphnia and copepods on microbial food web components. Freshwater Biol. 48(12): 2174-2193. 